\title{
Distributed and multifaceted effects of threat and safety
}

\author{
Kelly Morrow ${ }^{1}$, Murty Dinavahi ${ }^{1}$, Jongwan $\mathrm{Kim}^{1}$, Song- \\ tao Song ${ }^{1}$, Kesong $\mathrm{Hu}^{2}$, and Luiz Pessoa ${ }^{1}$ \\ 1 University of Maryland, College Park, MD, USA; 2 Lake Superior \\ State University, Sault St. Marie, MI, USA \\ pessoa@umd.edu; kmorrow@umd.edu \\ Draft of July 10, 2021
}

Sustained anticipation of unpredictable aversive events generates anticipatory processing that is central to anxiety. In the present functional Magnetic Resonance Study (fMRI) study, we examined how sustained threat is processed in the human brain. We used a relatively large sample $(N=109)$ and employed a Bayesian multilevel analysis approach to contrast threat and safe periods. Our analyses demonstrated that the effect of sustained threat is heterogeneous and distributed across the brain. Thus, the impact of threat is widespread, and not restricted to a small set of putatively emotion-related regions, such as the amygdala and the bed nucleus of the stria terminalis. Both transient and sustained, and increased and decreased responses during threat were observed. Our study reveals that transitioning between threat and safe states, and vice versa, leads to a widespread switch in brain responding that involves most of the brain.

Anxiety/fear related mental health conditions afflict a large number of individuals. In humans, the neural basis of threat processing has been intensively investigated in the last two decades. Anxious states induced by acute, unpredictable stressors have widespread effects on brain function due to changes in the organization of large-scale brain networks (Hermans et al., 2011, 2014; Kienast et al., 2008; Scott et al., 2006; Thomason et al., 2011)

Despite progress, several important questions remain unanswered:

1. If threat is sustained over periods of time (say, over 1o seconds), do brain responses exhibit sustained responses over the time interval in question? In other words, it is important to determine if a region's response is transient or sustained (Alvarez et al., 2011; Hasler et al., 2007; Hur et al., 2020; McMenamin et al., 2014; Schlund et al., 2013; Somerville et al., 2013).

2. Nonhuman research indicates that the amygdala plays a role in processing transient "fear"-related stimuli (e.g., a condiotioned 
stimulus) but the bed nucleus of the stria terminalis (BST) is implicated in sustained "anxious" processing (Davis and Shi, 1999; Walker et al., 2003). Such putative division of labor between the two structures is now debated (Canteras et al., 2009; Klumpers et al., 2017; Paré and Quirk, 2017; Tovote et al., 2015; Shackman and Fox, 2016).

3. Threat-related processing engages multiple brain regions, such that responses are stronger during threat compared to neutral conditions. However, growing evidence reveals that a complementary set of regions respond less strongly during threat relative to safe. For example, in a recent study, regions along the midline (including the posterior cingulate cortex, PCC) showed decreased responses for proximal vs. distal threat (Meyer et al., 2019), consistent with previous findings of the virtual tarantula paradigm by (Mobbs et al., 2010); see also (Yao et al., 2018). In particular, many regions that exhibit threat-related signal decreases appear to overlap with the default network. Thus, it is important to establish the relationship between threat-related decreases and the regions of the default network.

4. Most studies of temporally extended threat have performed analyses assuming that hemodynamic responses follow a canonical shape. Whereas this assumption is often reasonable for experimental paradigms with brief events, it is problematic when longer conditions are employed that generate responses that do not follow those based on the canonical shape; see, e.g., (Chen et al., 2015; Sreenivasan and D'Esposito, 2019). The ability to estimate response shape is particularly important when characterizing whether or not threat-related responses are transient or not (Hur et al., 2020).

5. Many previous studies of extended threat processing involved relatively modest sample sizes, and focused their analysis at the voxel level, a combination that results in relatively limited statistical power (Button et al., 2013; Cremers et al., 2017; Turner et al., 2018).

6. Another gap in the literature that is likely related to limited statistical power is the focus of studies on a relatively small set of brain regions, even though studies are performed at the whole-brain level. Because of this, we still lack important knowledge about the involvement of specific brain regions in the human brain during extended threat processing. For example, in rodents, the ventral striatum has been implicated in some forms of threat processing (Boeke et al., 2017), and sectors of the hippocampus play important roles in threat-related processing (Canteras et al., 2009; Tovote et al., 2015). As a further example, now in humans, although studies have reported threat-related responses in the cerebellum (Lange et al., 2015; Moreno-Rius, 2018), this structure has not been investigated in a more targeted manner. 
To address these gaps in the literature, we studied $N=109$ participants during an uncertain-threat paradigm (Figure 1). We focused on a set of 85 brain regions that have been discussed in the literature in the context of threat-related processing (Figure 2), and estimated the responses during threat and safe blocks without making responseshape assumptions.

We would like to highlight our statistical approach; see also (Chen et al., 2019; Gelman et al., 2012; Gelman and Hill, 2006; Limbachia et al., 2021). Whole-brain analysis with fMRI often lacks statistical power to uncover effects at the voxel level, which can lead to poor replicability. Therefore, here we sought to focus on a set of carefully delineated regions of interest (ROIs) and leverage the strengths of Bayesian multilevel modeling (Gelman and Hill, 2006; McElreath, 2018) (BML). One of the strengths of BML is that it allows the simultaneous estimation of multiple clustered parameters within a single model (in an educational setting, for example, the effects at multiple schools within a district). In the present context, BML allowed the estimation of the effects across multiple ROIs simultaneously, or voxels simultaneously (Chen et al., 2019). Among the advantages of this approach, information about the effect in one region/voxel can be shared across all regions/voxels (technically referred to as "partial pooling").

\section{Methods}

\section{Participants}

One hundred and nine right-handed participants ( 53 females; ages 18-35 years; average: 21.17 years, standard deviation: 2.59 years) with normal hearing, normal or corrected-to-normal vision, and no reported neurological disease or current us of psychoactive drug use were recruited from the University of Maryland, College Park, community. The study was approved by the University of Maryland, College Park, Institutional Review Board and all participants provided written informed consent before participating in the study. All were paid immediately after the experiment.

\section{Stimuli and behavioral paradigm}

To induce a sustained anxious states, a threat of shock paradigm was used while participants were scanned. Prior to scanning, participants completed the Trait Anxiety portion of the Spielberger State-Trait Anxiety Inventory (STAI) (Spielberger et al., 1970), and completed the State Anxiety portion immediately before scanning.

The experiment consisted of 3 runs over a two-hour session. Each run consisted of 8 threat and 8 safe blocks presented randomly. On each block, a colored circle was presented for 16.25 seconds via

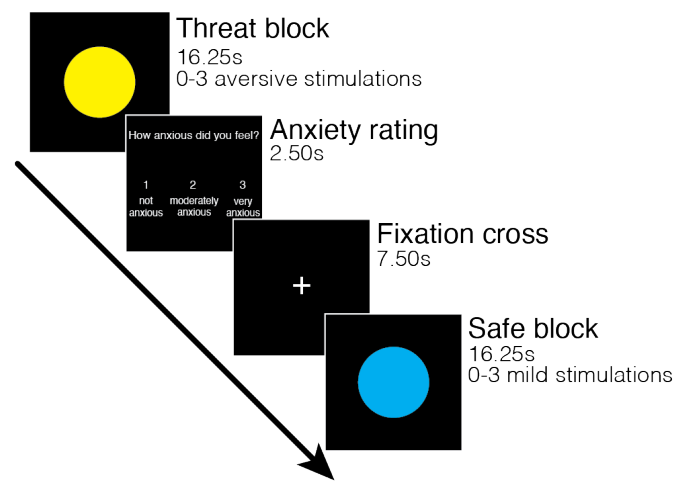

Figure 1: Paradigm. During the threat condition, signaled by a yellow circle, participants could receive o-3 aversive stimulations (shocks) over a period of 16.25 seconds. During the safe condition, signaled by a blue circle, participants could receive $0-3$ mild stimulations (vibration). After each block, participants rated their anxiety levels on a scale of $1-3$, followed by a 7.50 second fixation cross before the next block. 
bioRxiv preprint doi: https://doi.org/10.1101/2021.07.11.451944; this version posted July 11, 2021. The copyright holder for this preprint (which was not certified by peer review) is the author/funder, who has granted bioRxiv a license to display the preprint in perpetuity. It is made available under aCC-BY-ND 4.0 International license.

PsychoPy (www.psychopy.org). Prior to scanning, participants were informed that the color of the circle indicated whether a block was threat (yellow circle) or safe (blue circle). A threat circle indicated that they could receive zero to three highly unpleasant, but not painful electrical stimulations (referred to as "shock" here), whereas a safe circle indicated that they could receive zero to three very mild, but perceptible stimulations (referred to as "touch").

Both stimulation levels were set by the participant to reflect the desired intensities prior to scanning, and adjusted between runs, if needed. After each 16.25-second block, participants rated how anxious they felt during the block on a scale of 1-3 (1: not anxious, 2: moderately anxious, and 3: very anxious). Anxiety ratings were followed by a 7.50 second fixation cross before proceeding to the next trial. Because the ratings used by participants were largely correlated with block condition (i.e., higher ratings were indicated during threat blocks), we did not analyze ratings here.

Of the 48 trials in total, 32 trials ( 16 threat and 16 safe) contained zero stimulations and the remaining 16 trials ( 8 threat and 8 safe) had at least one instance of stimulation.

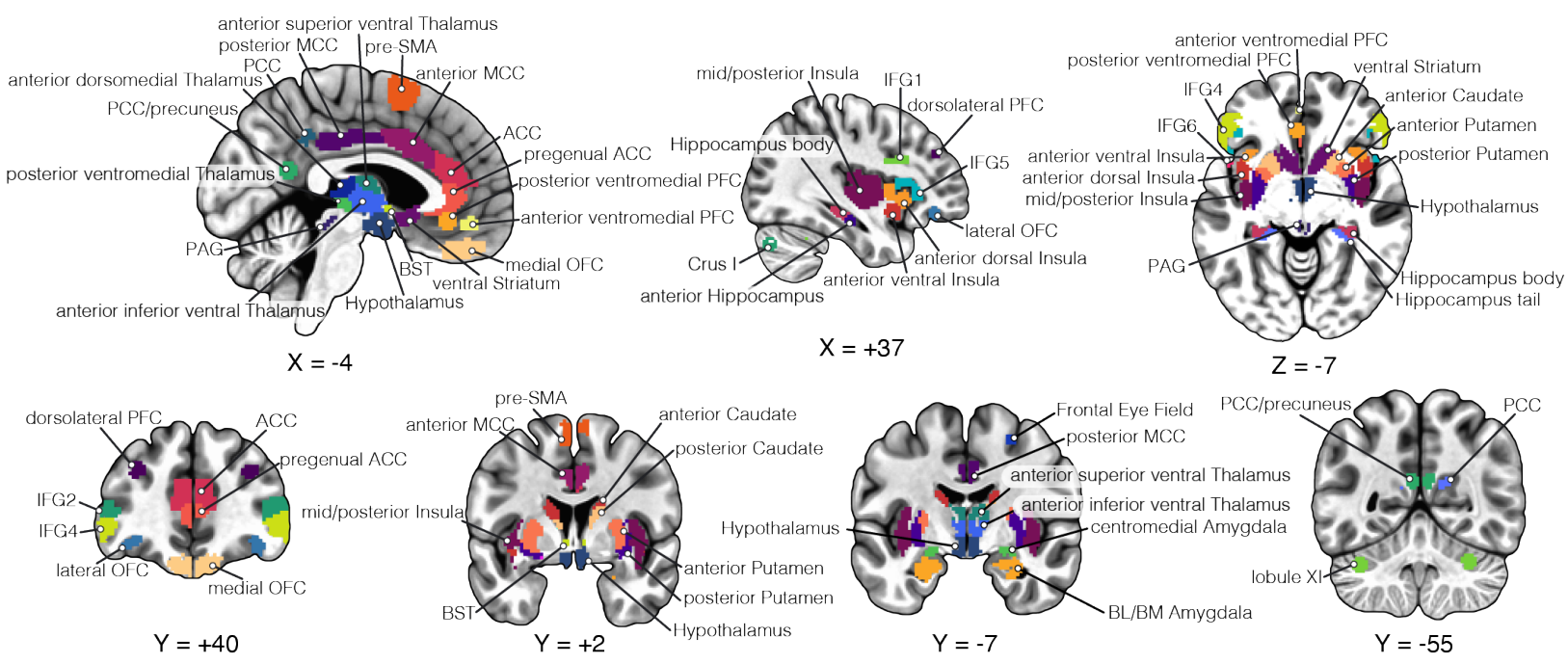

\section{MRI data acquisition}

MRI data collection used a 3 T Siemens TRIO scanner (Siemens Medical Systems) with a 32-channel head coil. First, we acquired a highresolution T1-weighted MPRAGE anatomical scan (TR: $2400 \mathrm{~ms}$, TE: $2.01 \mathrm{~ms}$, FOV: $256 \mathrm{~mm}$, voxel size: o.8-mm isotropic). Subsequently, we collected functional echo planar image (EPI) volumes over three runs (340 images per run) using a multiband scanning sequence with $\mathrm{TR}=1250 \mathrm{~ms}, \mathrm{TE}=39.4 \mathrm{~ms}, \mathrm{FOV}=210 \mathrm{~mm}$, and multiband factor $=$ 6. Each volume contained 66 non-overlapping oblique slices oriented
Figure 2: Regions of interest. Brain regions analyzed. Abbreviations: ACC; anterior cingulate cortex, MCC; midcingulate cortex, PCC; posterior cingulate cortex, BL/BM amygdala; basolateral/basomedial amygdala, BST; bed nucleus of the stria terminalis, IFG; inferior frontal gyrus, OFC; orbitofrontal cortex, PAG; periaqueductal gray, PFC; prefrontal cortex, pre-SMA; pre-supplementary motor area. 
bioRxiv preprint doi: https://doi.org/10.1101/2021.07.11.451944; this version posted July 11, 2021. The copyright holder for this preprint (which was not certified by peer review) is the author/funder, who has granted bioRxiv a license to display the preprint in perpetuity. It is made available under aCC-BY-ND 4.0 International license.

30 degrees clockwise relative to the AC-PC axis; thus voxels were $2.2 \mathrm{~mm}$ isotropic. Double-echo field maps $(\mathrm{TE}=73.0 \mathrm{~ms}$ ) were also acquired with acquisition parameters matched to the functional data.

\section{Skin conductance response acquisition}

Skin conductance responses (SCR) were collected using the MP-150 data acquisition system (BIOPAC Systems, Inc., Goleta, CA) with the GSR $100 \mathrm{C}$ module. Signals were acquired at $250 \mathrm{~Hz}$ using MRIcompatible electrodes attached to the index and middle fingers of the participants' non-dominant, left hand. SCR data from two subjects ( 1 female, 1 male) were not collected due to technical problems.

\section{Regions of interest (ROIs)}

We focused on 85 structurally and functionally defined cortical and subcortical regions of interest (shown in Figures 3 and 4). Functional masks were based on data from separate studies, not the present one. Potential contributions of white matter and cerebrospinal fluid were minimized by excluding voxels that intersected with masks of these tissue types. All ROIs were disjoint, such that no overlap occurred between them.

\begin{tabular}{|c|c|c|c|c|}
\hline Region & Type & Voxel extent $(R, L)$ & Origin & Description \\
\hline medial OFC & probalistic & 407,339 & $\begin{array}{l}\text { Julich Brain atlas; Amunts et al., } \\
\text { 2020; Wojtasik et al, } 2020\end{array}$ & probability threshold $=0.60$, midline clipped \\
\hline lateral OFC & probalistic & 56,62 & $\begin{array}{l}\text { Julich Brain atlas; Amunts et al., } \\
\text { 2020; Wojtasik et al, } 2020\end{array}$ & probability threshold $=0.60$ \\
\hline anterior ventromedial PFC & functional & 67 & Meyer et al., 2019 & $5 \mathrm{~mm}$ sphere of threat proximity cluster \\
\hline posterior ventromedial PFC & functional & 81 & Boeke et al, 2017 & $5 \mathrm{~mm}$ sphere based on coordinates \\
\hline inferior frontal gyrus 1 & probalistic & 329,304 & Brainnetome atlas; Fan et al., 2016 & \\
\hline inferior frontal gyrus 2 & probalistic & 293,337 & Brainnetome atlas; Fan et al., 2016 & \\
\hline inferior frontal gyrus 3 & probalistic & 313,264 & Brainnetome atlas; Fan et al., 2016 & \\
\hline inferior frontal gyrus 4 & probalistic & 349,323 & Brainnetome atlas; Fan et al., 2016 & \\
\hline inferior frontal gyrus 5 & probalistic & 525,434 & Brainnetome atlas; Fan et al., 2016 & \\
\hline inferior frontal gyrus 6 & probalistic & 260,261 & Brainnetome atlas; Fan et al., 2016 & \\
\hline dorsolateral PFC & functional & 75,75 & Hur et al., 2020 & $5 \mathrm{~mm}$ sphere based on Threat $>$ Safe coordinates \\
\hline Frontal Eye Field & functional & 81,33 & Toro et al., 2008 & $5 \mathrm{~mm}$ spheres based on report MNI coordinates \\
\hline anterior ventral Insula & probalistic & 176,171 & Hammers atlas; Faillenot et al, 2017 & probability threshold $=0.50$; anterior pole mask \\
\hline anterior dorsal Insula & probalistic & 235,236 & Hammers atlas; Faillenot et al, 2017 & $\begin{array}{c}\text { probability threshold }=0.50 \text {; anterior short \& middle } \\
\text { short gyri union }\end{array}$ \\
\hline $\mathrm{mid} /$ posterior Insula & probalistic & 572,533 & Hammers atlas; Faillenot et al, 2017 & $\begin{array}{l}\text { probability threshold }=0.50 ; \text { posterior short, anterior } \\
\text { long, and posterior long gyri union }\end{array}$ \\
\hline Pregenual anterior cingulate & structural & 143,137 & $\begin{array}{l}\text { Desikan-Killany atlas; Desikan et al., } \\
2006\end{array}$ & $\begin{array}{l}\text { overlap with vmPFC and ACC excluded; midline } \\
\text { excluded }\end{array}$ \\
\hline $\mathrm{ACC}$ & structural & 346,364 & Brainnetome atlas; Fan et al., 2016 & overlap with aMCC excluded; midline excluded \\
\hline anterior MCC & structural & 382,302 & Destrieux et al., 2010 & midline excluded \\
\hline posterior MCC & structural & 369,245 & $\begin{array}{l}\text { Desikan-Killany atlas; Desikan et al., } \\
2006\end{array}$ & overlap with aMCC excluded; midline excluded \\
\hline medial PCC & functional & 64 & Meyer et al., 2019 & Based on previous functional data \\
\hline PCC & functional & 52,34 & Meyer et al., 2019 & Based on previous functional data \\
\hline PCC/precuneus & functional & 60,57 & Meyer et al., 2019 & Based on previous functional data \\
\hline pre-SMA & probalistic & 227,213 & $\begin{array}{l}\text { Julich brain atlas; Amunts et al., } \\
\text { 2020; Ruan et al., } 2018\end{array}$ & probability threshold $=0.50 ;$ midline excluded \\
\hline
\end{tabular}

All ROI masks were multiplied with a gray matter mask to reduce contribution of cerebrospinal fluid and white matter in data. Abbreviations: L, left; R, right; OFC, orbitofrontal cortex; PFC, prefrontal cortex; pre-SMA, pre-supplementary motor area.

\section{Data preprocessing}

Functional images were preprocessed as described in our previous work by using a combination of fMRI packages and in-house scripts 
bioRxiv preprint doi: https://doi.org/10.1101/2021.07.11.451944; this version posted July 11, 2021. The copyright holder for this preprint (which was not certified by peer review) is the author/funder, who has granted bioRxiv a license to display the preprint in perpetuity. It is made available under aCC-BY-ND 4.0 International license.

\begin{tabular}{|c|c|c|c|c|}
\hline Region & Type & Voxel extent (R, L) & Origin & Description \\
\hline ventral Striatum & functional & 241,300 & Pauli et al., 2016 & \\
\hline anterior Caudate & functional & 488,364 & Pauli et al., 2016 & \\
\hline posterior Caudate & functional & 124,214 & Pauli et al., 2016 & \\
\hline anterior Putamen & functional & 339,346 & Pauli et al., 2016 & \\
\hline posterior Putamen & functional & 268,239 & Pauli et al., 2016 & \\
\hline BST & structural & 8,9 & Theiss et al., 2017 & \\
\hline centromedial Amygdala & structural & 45,35 & Nacewicz et al., 2014 & Combination of central and medial Amygdala masks \\
\hline BL/BM Amygdala & structural & 129,132 & Nacewicz et al., 2014 & $\begin{array}{l}\text { Combination of basolateral and basomedial Amygdala } \\
\text { masks }\end{array}$ \\
\hline anterior Hippocampus & functional & 333,331 & Melbourne subcortical atlas; Tian et al., 2020 & Scale 3 of Melbourne atlas (second finest parcellation) \\
\hline Hippocampus body & functional & 192,190 & Melbourne subcortical atlas; Tian et al., 2020 & Scale 3 of Melbourne atlas \\
\hline Hippocampus tail & functional & 92,102 & Melbourne subcortical atlas; Tian et al., 2020 & Scale 3 of Melbourne atlas \\
\hline Hypothalamus & structural & 169,170 & Pauli et al., 2018 & \\
\hline anterior superior ventral Thalamus & functional & 161,122 & Melbourne subcortical atlas; Tian et al., 2020 & Scale 3 of Melbourne atlas \\
\hline anterior inferior ventral Thalamus & functional & 244,190 & Melbourne subcortical atlas; Tian et al., 2020 & Scale 3 of Melbourne atlas \\
\hline posterior ventrolateral Thalamus & functional & 16,20 & Melbourne subcortical atlas; Tian et al., 2020 & Scale 3 of Melbourne atlas \\
\hline posterior ventromedial Thalamus & functional & 79,82 & Melbourne subcortical atlas; Tian et al., 2020 & Scale 3 of Melbourne atlas \\
\hline anterior dorsolateral Thalamus & functional & 49,77 & Melbourne subcortical atlas; Tian et al., 2020 & Scale 3 of Melbourne atlas \\
\hline anterior dorsomedial Thalamus & functional & 171,170 & Melbourne subcortical atlas; Tian et al., 2020 & Scale 3 of Melbourne atlas \\
\hline PAG & structural & 15,24 & Ezra et al., 2015 & \\
\hline Lobule XI (Cerebellum) & functional & 109,122 & $\begin{array}{c}\text { Hur et al., 2020; see map: } \\
\frac{\text { https://identifiers.org/neurovault.collection:858 }}{\underline{3}}\end{array}$ & $\begin{array}{l}\text { 6-mm spheres created from uncertain threat }>\text { uncertain } \\
\text { safe functional map }\end{array}$ \\
\hline Crus I (Cerebellum) & functional & 105,119 & Krienen \& Buckner, 2009 & 6-mm spheres created from peak coordinates \\
\hline
\end{tabular}

All ROI masks were multiplied with a gray matter mask to reduce contribution of cerebrospinal fluid and white matter in data. Abbreviation: L, left; R, right; BST, bed nucleus of the stria terminalis; PAG, periaqueductal gray.

(Limbachia et al., 2021). Slice-timing correction was performed with the Analysis of Functional Neuroimages (AFNI; (Cox, 1996)) 3dTshift with Fourier interpolation to align the onset times of each slice in a volume to the first acquired slice. For voxelwise analysis (but not ROI level), data were spatially smoothed with a Gaussian filter (4 mm full-width half-maximum) restricted to gray matter voxels. Signal intensity at each voxel was normalized to a mean value of 100 separately for each run. To further reduce the contribution of head motion artifacts, FSL's Independent Component Analysis, Automatic Removal of Motion Artifacts (ICA-AROMA) toolbox was applied (Pruim et al., 2015). Components classified as head motion were regressed out of the data using FSL's fsl_regfilt.

Given the small size of some of our regions of interest, following previous work (Limbachia et al., 2021), we sought to improve coregistration between functional and anatomical images using a "voting scheme" to determine whether or not a voxel belonged to the brain (i.e., skull stripping). To do so, we employed six different fMRI packages (ANTs: Avants et al. (2009), AFNI: Cox (1996), ROBEX: Iglesias et al. (2011), FSL: Smith et al. (2004), SPM: Friston et al. (2007), and BrainSuite: Shattuck and Leahy (2002)). Based on T1 structural data, if 4/6 packages estimated a voxel to belong to the brain, it was retained, otherwise it was discarded. Next, ANTs was used to estimate a nonlinear transformation mapping the skull-stripped anatomical T1 image to the skull-stripped MNI152 template (interpolated to 1-mm isotropic voxels). The nonlinear transformations from coregistration/unwarping and normalization were combined into a single transformation that was applied to map volume-registered functional volumes to standard space (interpolated to $2-\mathrm{mm}$ isotropic voxels).

Preprocessed functional data were then subjected to run-wise motion thresholding. Any particular run that exceeded a mean framewise displacement of $0.5 \mathrm{~mm}$, had a total framewise displacement of

Figure 4: Subcortical regions of interest. 
$5 \mathrm{~mm}$ or more, or had $20 \%$ or more of all TRs with framewise displacement over $0.5 \mathrm{~mm}$ was excluded. Runs were then concatenated for each subject.

Temporal signal-to-noise ratio, defined as the ratio of mean to standard deviation across time, can be rather low in some brain areas, including the orbitofrontal cortex, amygdala, and periaqueductal gray. Voxels that did not meet our criteria were discarded from analysis $(0.21 \pm 0.47 \%$ of voxels). Voxels were excluded if their mean (after signal normalization to 100) was outside the range 95-105, or the standard deviation exceeded 25.

\section{Subject-level analysis}

To estimate the shape of the responses during threat and safe blocks, we focused on the 16 blocks of each block type with no electrical stimulation. Response shape was estimated by employing a series of cubic spline basis functions (similar to the "finite impulse response" method also commonly adopted). The analysis utilized subject-level multiple linear regression with AFNI's 3dREMLfit program.

At the ROI level, the analysis employed the average timeseries (unsmoothed data) across ROI voxels. At the voxel level, spatially smoothed data were used to increase signal to noise, as routinely done in fMRI analysis. Blocks of a given type were modeled with 14 regressors (i.e., cubic splines) aligned to the TRs of the block starting at block onset (so starting at $t=0$ and ending with the TR starting at $t=16.25)$.

The anxiety rating period, which was not of interest here, was modeled by convolving a square wave with a canonical hemodynamic response. Likewise, the remaining blocks containing at least one stimulation event were modeled by convolving the block duration (16.25 seconds) with a canonical filter. To minimize contamination of task-related signal with electrical stimulation events, the 15 seconds following each stimulation were censored from analysis.

Separately, we estimated the responses to stimulation events to confirm the presence of robust responses in regions like the amygdala. In this case, the cubic spline regressors were aligned to the stimulation (shock or touch) onset. Finally, all analyses included a set of regressors modeling head motion parameters (six rigid body motion parameters and their discrete temporal derivatives), in addition to linear and nonlinear polynomial terms (up to third order) to account for baseline and slow signal drift.

\section{Group Bayesian multilevel analysis: ROI level}

Employing a single multilevel model allowed the contributions to fMRI signals of subject-level effects (i.e., subject effect across conditions) and ROI-level effects (i.e., ROI effect across subjects) to be estimated simultaneously with the condition effect (threat versus safe). The input to the model consisted of 85 averaged-across-voxels time series from the first level described above, as in our previous 
work (Limbachia et al., 2021). The model was estimated using the brms R package (Bürkner, 2017) which utilizes rstan (https://mcstan.org/users/interfaces/rstan), the $\mathrm{R}$ interface to the Stan probabilistic language (https://mc-stan.org).

We considered two temporal time windows: early (2.5-8.75 seconds from block onset) and late (10-16.25 seconds). Note that responses at $\mathrm{o}$ and 1.25 seconds were not used to account for the latency of the hemodynamic response. For each window, we defined response magnitude as the sum of the responses across the window. In doing so, our goal was to create something akin to an "area under the curve" response measure (Chen et al., 2015). However, experimental conditions do not have a common baseline across subjects or ROIs. Thus, response estimates at each time point (per subject and ROI) will potentially have negative and positive values across time that may "cancel out" each other if summed across the temporal window of interest, potentially leading to response magnitudes close to zero because negative and positive values were simply summed (see, for example, Figure 10). Accordingly, to determine response measures, response estimates were minimum-shifted, resulting in positive values only, for each subject and ROI, separately (note that the original estimated responses are shown in the figures).

Given our within-subject design, we used the difference between threat and safe response magnitudes as the variable to be tested: $\Delta_{s, r}$, where $s$ indexes subjects, and $r$ indexes ROI. For computational expediency, we analyzed the two time windows separately taking into account anxiety-related covariates. In standard linear mixed-effects modeling notation our model was defined as

$$
\Delta_{s, r} \sim 1+\text { State }+ \text { Trait }+(1 \mid \text { Sub })+(1+\text { State }+ \text { Trait } \mid \text { ROI }),
$$

where Sub (Subject) and ROI are grouping variables. State and Trait indicate the covariates of the model. The terms " 1 " indicate intercept terms, including an overall intercept and so-called varying intercepts per subject (subject-specific contribution) and per ROI (ROI-specific contribution). The notation $(1+$ State + Trait|ROI) summarizes the varying intercepts and slopes per ROI, but also the correlation structure between intercept and slopes.

Model estimation generates a single posterior that is a joint distribution in a high-dimensional parameter space. Posteriors for each effect at the ROI-level were calculated by summing the relevant contributions (i.e., overall intercept term and intercept at the ROI level). Note whereas posteriors can be plotted separately for each ROI for visualization purposes (Figures 7 and 8), they should be understood as belonging to a single joint distribution.

Bayesian estimation requires the specification of prior distributions for all the parameters of interest in the model. We employed so-called weakly informative priors that help estimation convergence (all $\hat{R}<1.1$, as recommended), but have negligible impact on estimated parameters, especially with reasonable sample sizes. We provide a complete description of the Bayesian formulation of 
the model, together with the priors, in the following GitHub page: https://github.com/LCE-UMD/mood-anxiety.

\section{Group Bayesian multilevel analysis: Voxel level}

We performed voxel-level BML analysis of insula and amygdala data, separately. The analysis entailed adding a voxel level to the model above. In addition, instead of using the original ROI definitions, we created finer parcellations for the insula and amygdala. Thus, the 941 voxels of the entire left insula were clustered into 11 ROIs, and the 986 voxels of entire right insula were clustered into 1o ROIs. Similarly, the 167 voxels of the entire left amygdala were clustered into 6 ROIs, and the 176 voxels of entire right amygdala were clustered into 6 ROIs. In all cases, the new smaller ROIs respected the original ROI boundaries investigated in the region-level analysis (e.g., new insula ROIs did not include voxels from both the ventral and dorsal insula; or correspondingly, from the centromedial and the basolateral amygdala). Smaller ROIs were created by clustering adjacent voxels based on their $\{x, y, z\}$ coordinates (not time series data) with standard $k$-means clustering.

The motivation for having finer parcellations of the insula and amygdala was related to the concept of partial pooling in multilevel modeling. By having a larger number of ROIs, the pooling effect (that is, voxel effects possibly being pushed to some extent to the overall average of the ROI), was more strongly restricted to the local ROI to which a voxel belonged, thus respecting the idea that information exchange should tend to stay local (technically speaking, partial pooling depends on the variance of voxel-level estimates). Overall, the modeling approach followed the same strategy as that of the the ROI-level analysis, with the addition of the voxel-level data:

$$
\Delta_{S, r, v} \sim 1+(1 \mid \mathrm{Sub})+(1 \mid \mathrm{ROI})+(1 \mid \mathrm{VOX}),
$$

where $s, r$, and $v$ index subject, (small) ROI, and voxel, respectively. For computational expediency, covariates were not included in the models. In addition, for the insula, separate models were applied to the left and right insula. Because the number of voxels in the amygdala was relatively small, we included an additional hemisphere level in the equation above, and a single model was run. Again, convergence of estimates was observed in all cases $(\hat{R}<1.1$, as recommended).

\section{Skin conductance}

As stated, data were acquired at $250 \mathrm{~Hz}$. For each run, we detrended the signal by removing the best linear fit to the data. Subsequently, we applied a median filter over 50-sample windows (200 $\mathrm{ms})$ to remove 


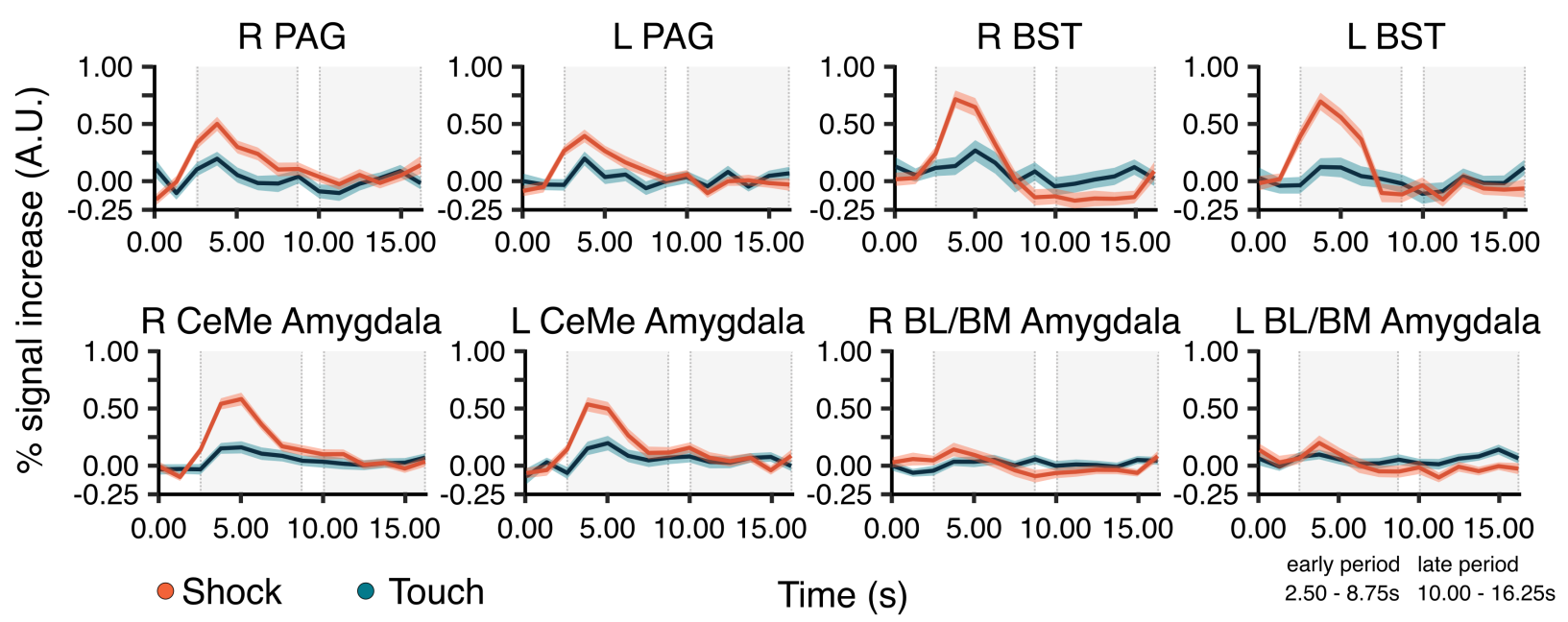

high-frequency noise.

\section{Results}

We report the results of Bayesian multilevel analysis (BML) performed on 85 regions (one representative time series per ROI obtained by averaging unsmoothed functional data to preserve spatial resolution). Currently, whole-brain voxelwise BML analysis is not computationally feasible. Accordingly, we performed voxelwise analysis in two regions important for threat-related processing, namely the insula and the amygdala. In all Bayesian analyses, statistical evidence for effects is reported in terms of $P^{+}$, the probability that the effect is greater than zero based on the posterior distribution: values closer to 1 provide evidence that the effect of interest is greater than zero (threat $>$ safe) while values closer to zero convey support for the inverse effect (safe $>$ threat). We treat Bayesian probability values as providing a continuous amount of support for a given hypothesis; thus not dichotomously as "significant" vs. "not significant". ${ }^{1}$

Because Bayesian multilevel modeling implements so-called partial pooling of the estimates across voxels (when present), regions, as well as participants, the process tends to generate estimates that are more conservative; for example, they will be closer to the average effect within a given region than if each voxel's effect were estimated individually. Effectively, the approach allows information to be shared across spatial units and tends to stabilize the effect estimates. Because of this conservative nature, some statisticians have suggested that adjustment for multiplicity is not needed (Gelman et al., 2012), especially since all the inferences are drawn from a single, overall posterior distribution of an integrative model. We follow this approach here; for detailed discussion, see (Chen et al., 2021).
Figure 5: Hemodynamic responses to shock and touch. Estimated responses averaged across subjects. Error bands show $95 \%$ interval for standard error across participants to illustrate variability only. Shaded regions represent early and late periods. Abbreviations: L: Left, R: Right, PAG: periaqueductal grey, BST: bed nucleus of stria terminalis, CM: centromedial, BL/BM: basolateral/basomedial.

${ }^{1}$ Readers may choose to apply thresholds, although we find such approach unproductive; For in-depth discussion, see (Chen et al., 2020, 2021). 


\section{Hemodynamic responses to shock and skin conduc- tance responses during threat blocks}

To verify that shock delivery evoked clear hemodynamic responses, we estimated responses evoked by stimulus administration. Large, transient responses were observed across many brain regions (Figure 5; note the scale of the responses). Note that robust differential responses were not observed in the basal amygdala.

Analysis of skin conductance revealed transient responses following the onset of threat blocks that was not seen in safe blocks (Figure 6). It is noteworthy that, although stimulation events spanned the duration of a block, autonomic arousal indexed by skin conductance response was not sustained.

\section{ROI-level analysis}

A broad set of brain regions involved in multiple aspects of threatrelated processing were considered for analyses (Figure 2). For each ROI, responses were characterized based on two temporal windows of a block: an early window from 2.50 to 8.75 seconds and a late window from 10.00 to 16.25 seconds after block onset. The average response from each window was considered the response strength for a given condition.

The results are summarized via a series of posterior distributions, one for each brain region (Figures 7 and 8). To illustrate these results, Figure 9 shows probability values on brain slices for the early and late periods. We see very strong support (say, $P^{+}>0.990$ ) for threat $>$ safe in both early and late periods for multiple regions, as well as strong statistical support for many other regions. A similar picture was observed for threat $<$ safe effects (this time with $P^{+}$values very close to zero).

We show estimated responses across multiple sets of regions to illustrate the types of responses observed, including transient and sustained responses. Figure 1o shows responses in a few key brain regions. We observed robust response decreases during threat, which we illustrate in Figure 11. An additional set of "noteworthy" regions is displayed in Figure 12. Figure 13 shows responses in the striatum. Finally, Figure 14 shows responses in the thalamus.

\section{Voxel-level analysis}

To characterize the spatial distribution of effects in the insula and amygdala, we performed voxelwise BML analysis. The results were in line with the ROI-level findings. For the insula (Figure 15), increased responses with threat were observed almost entirely in the dorsal anterior insula. In contrast, in the posterior insula, responses were stronger during safe. For the amygdala (Figure 16), the results followed what was found with the ROI-level analysis, but a spatial pattern of effect strength was also evident, with weaker evidence

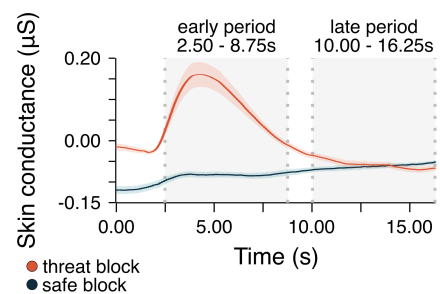

Figure 6: Skin conductance responses for safe and threat blocks. Skin conductance responses averaged across 107 subjects (solid lines) for safe (dark blue) and threat (red) blocks. Error bands show 95\% interval for standard error across participants to illustrate variability only. Shaded regions represent early and late periods. 
bioRxiv preprint doi: $h t t p s: / / d o i . o r g / 10.1101 / 2021.07 .11 .451944$; this version posted July 11, 2021. The copyright holder for this preprint (which was not certified by peer review) is the author/funder, who has granted bioRxiv a license to display the preprint in perpetuity. It is made available under aCC-BY-ND 4.0 International license.

Early period (2.50 - 8.75 seconds)

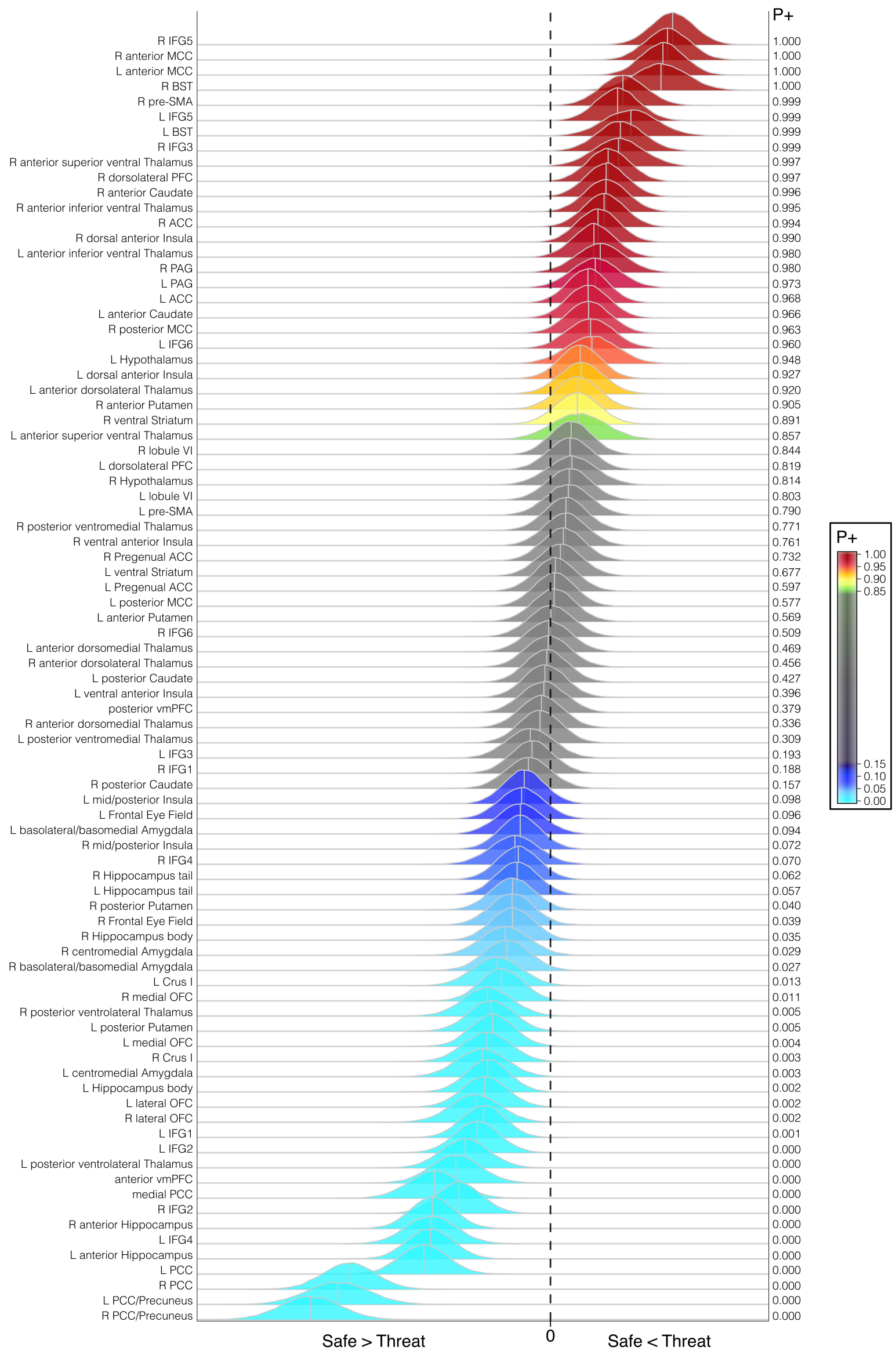

Figure 7: Posterior distributions: Early period. The posteriors show the distribution of the difference between threat and safe. $P^{+}$is the probability that the effect is greater than zero. 
bioRxiv preprint doi: https://doi.org/10.1101/2021.07.11.451944; this version posted July 11, 2021. The copyright holder for this preprint (which was not certified by peer review) is the author/funder, who has granted bioRxiv a license to display the preprint in perpetuity. It is made available under aCC-BY-ND 4.0 International license.

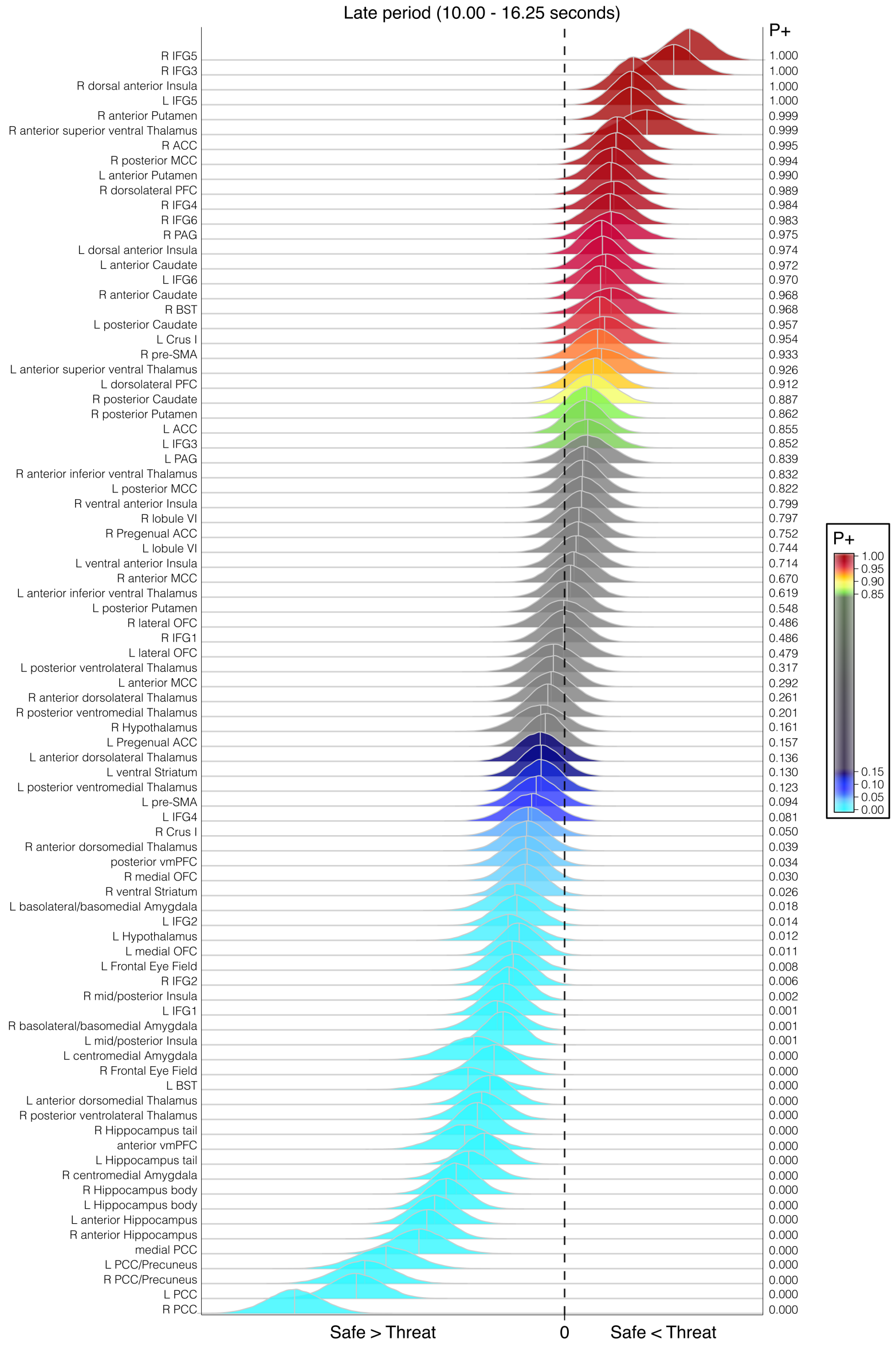

Figure 8: Posterior distributions: Late period. The posteriors show the distribution of the difference between threat and safe. $P^{+}$is the probability that the effect is greater than zero. 
bioRxiv preprint doi: https://doi.org/10.1101/2021.07.11.451944; this version posted July 11, 2021. The copyright holder for this preprint (which was not certified by peer review) is the author/funder, who has granted bioRxiv a license to display the preprint in perpetuity. It is made available under aCC-BY-ND 4.0 International license.
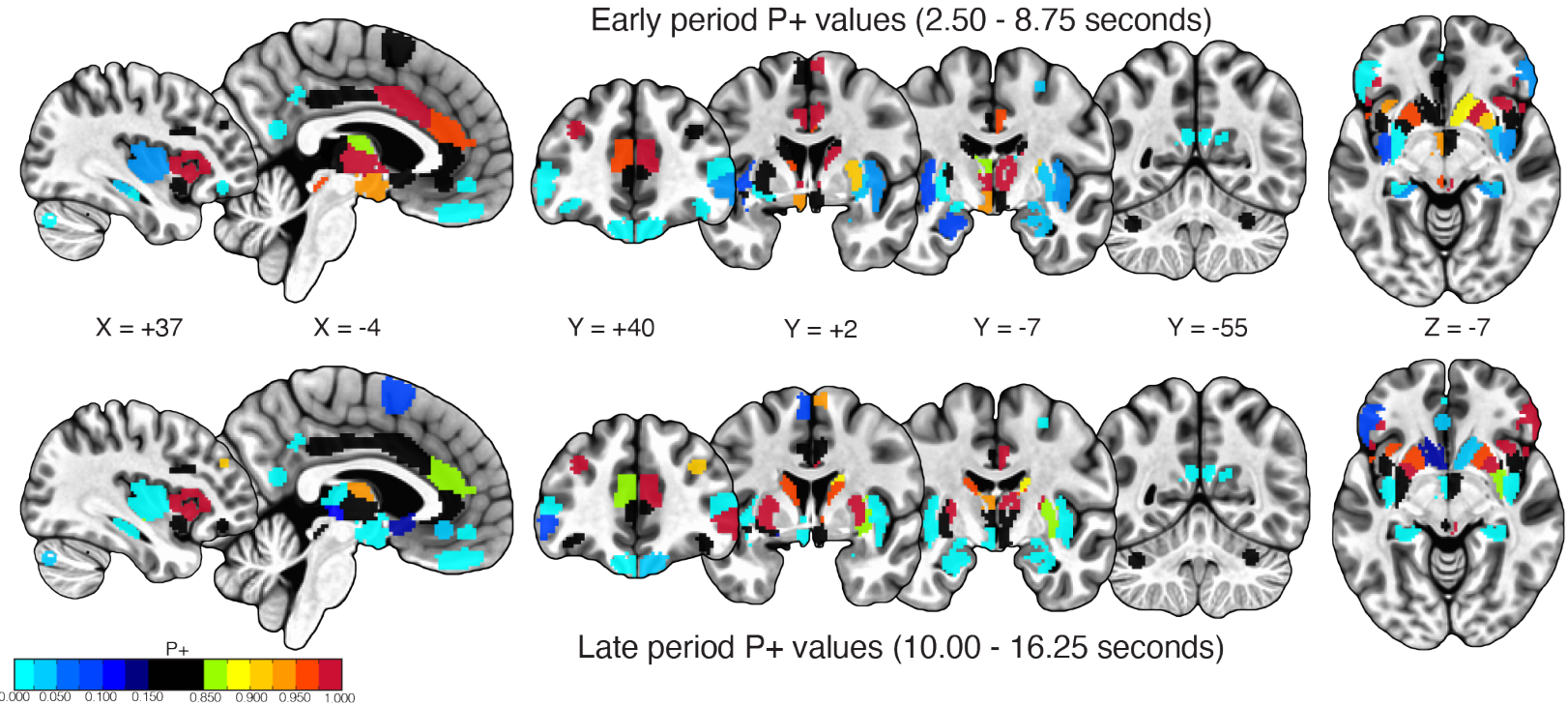

Late period $\mathrm{P}+$ values (10.00 - 16.25 seconds)

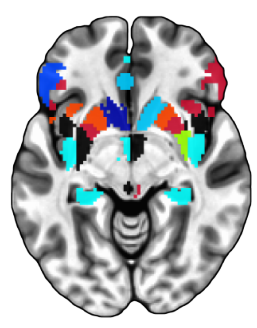

Figure 9: Contrast of threat vs. safe. Probability that threat $>$ safe effect is great than zero during early and late periods. Values closer to 1 indicate greater responses during threat blocks, and values closer to o indicate greater activity during safe blocks. Brain slices correspond to those in Figure 2.

$R$ ventral anterior Insula

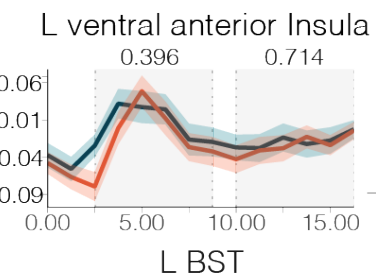

\section{R dorsal anterior Insula}

L dorsal anterior Insula
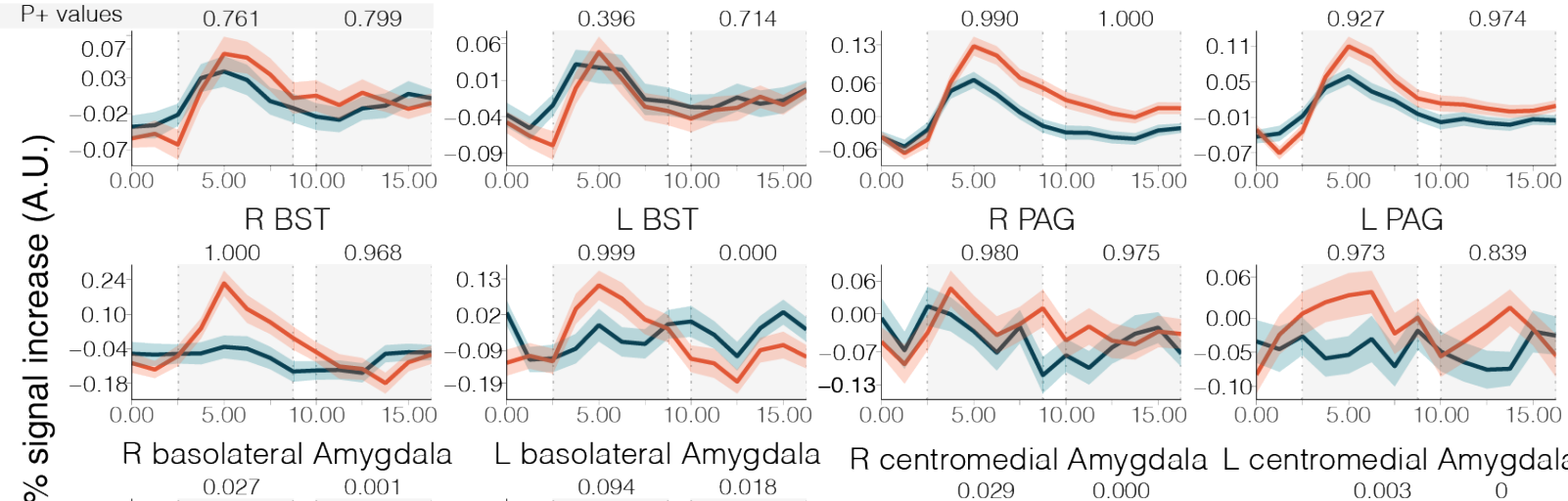

LPAG

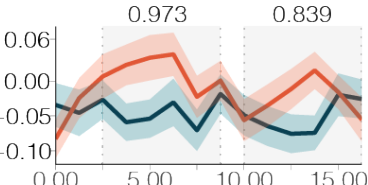

$\mathrm{L}$ basolateral Amygdala

$\mathrm{R}$ centromedial Amygdala $\mathrm{L}$ centromedial Amygdala
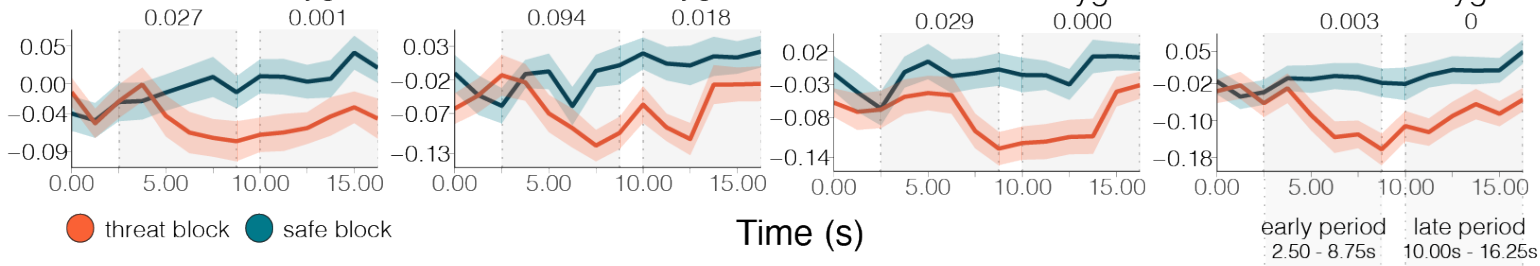

Figure 10: Estimated responses across key regions. Error bands show $95 \%$ interval for standard error across participants to illustrate variability only. 
bioRxiv preprint doi: https://doi.org/10.1101/2021.07.11.451944; this version posted July 11, 2021. The copyright holder for this preprint (which was not certified by peer review) is the author/funder, who has granted bioRxiv a license to display the preprint in perpetuity. It is made available under aCC-BY-ND 4.0 International license.
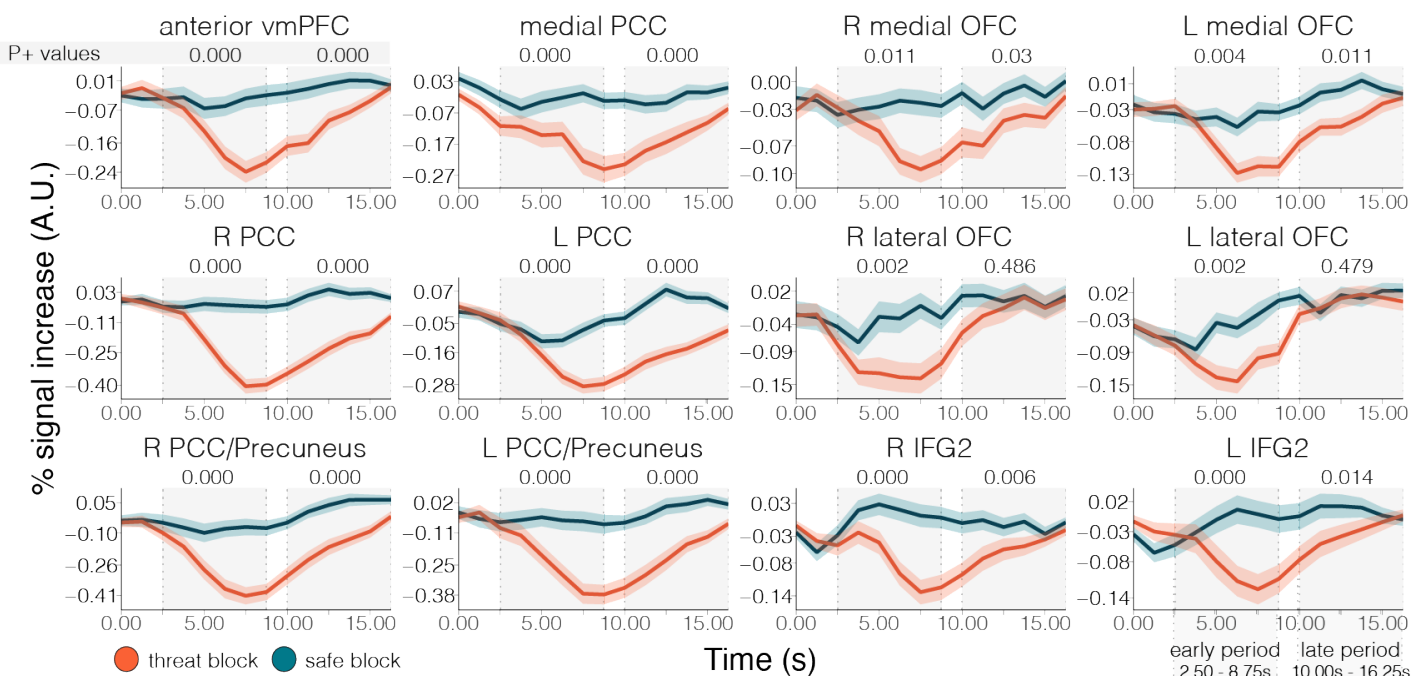

L IFG2

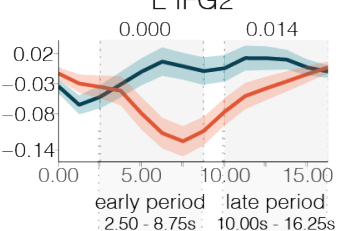

Time (s)

Figure 11: Estimated responses across regions exhibiting decreased responses during threat. Error bands show 95\% interval for standard error across participants to illustrate variability only.
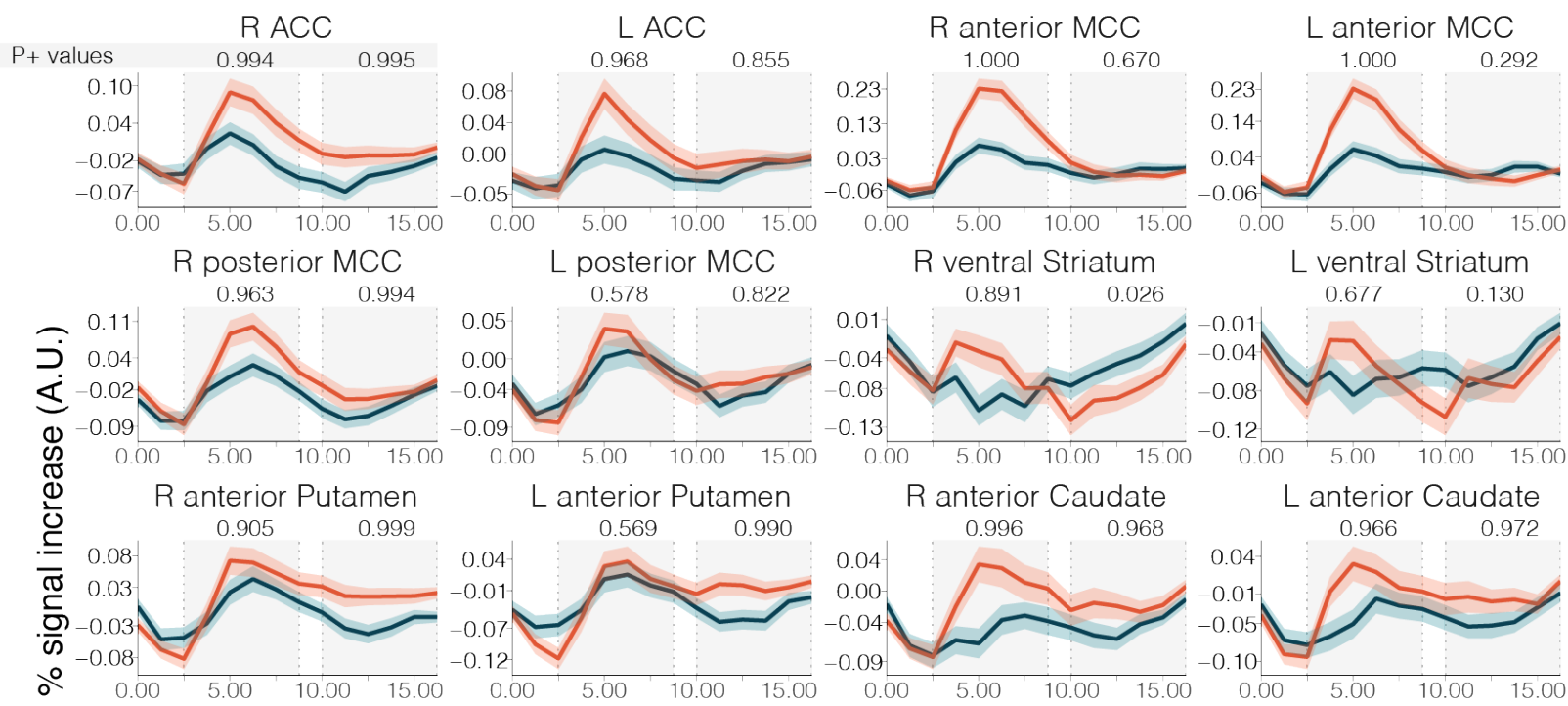

$\mathrm{R}$ ventral Striatum
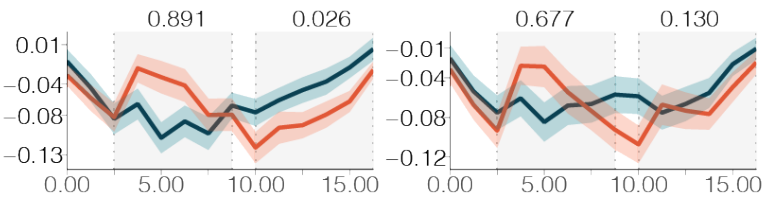

anterior Putamen

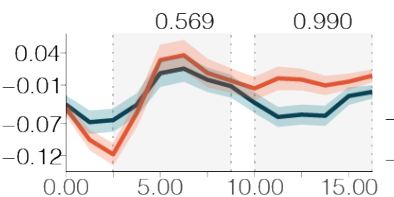

$\mathrm{R}$ anterior Caudate

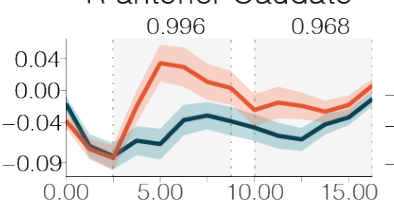

$\mathrm{L}$ anterior Caudate

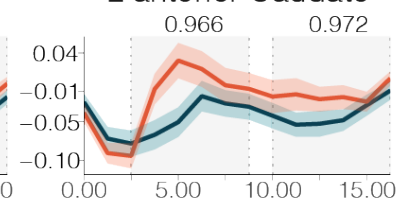

R anterior Hippocampus $L$ anterior Hippocampus

R Hypothalamus
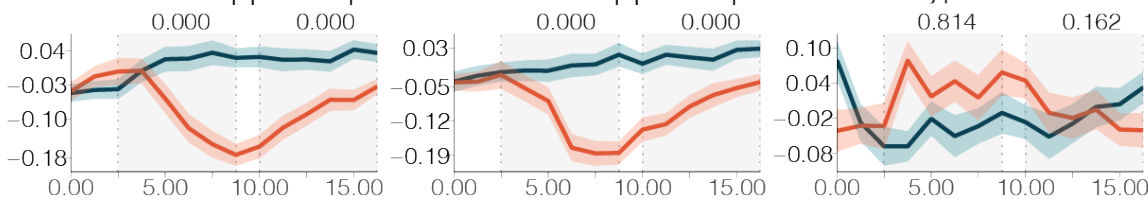

L Hypothalamus

threat block safe block

Time (s)

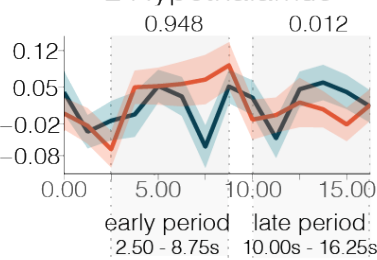

Figure 12: Estimated responses across additional regions. Error bands show $95 \%$ interval for standard error across participants to illustrate variability only. 
bioRxiv preprint doi: https://doi.org/10.1101/2021.07.11.451944; this version posted July 11, 2021. The copyright holder for this preprint (which was not certified by peer review) is the author/funder, who has granted bioRxiv a license to display the preprint in perpetuity. It is made available under aCC-BY-ND 4.0 International license.

16

in more ventral parts of the amygdala. In other words, in the ventral amygdala, responses to threat and safe tended to be relatively similar.

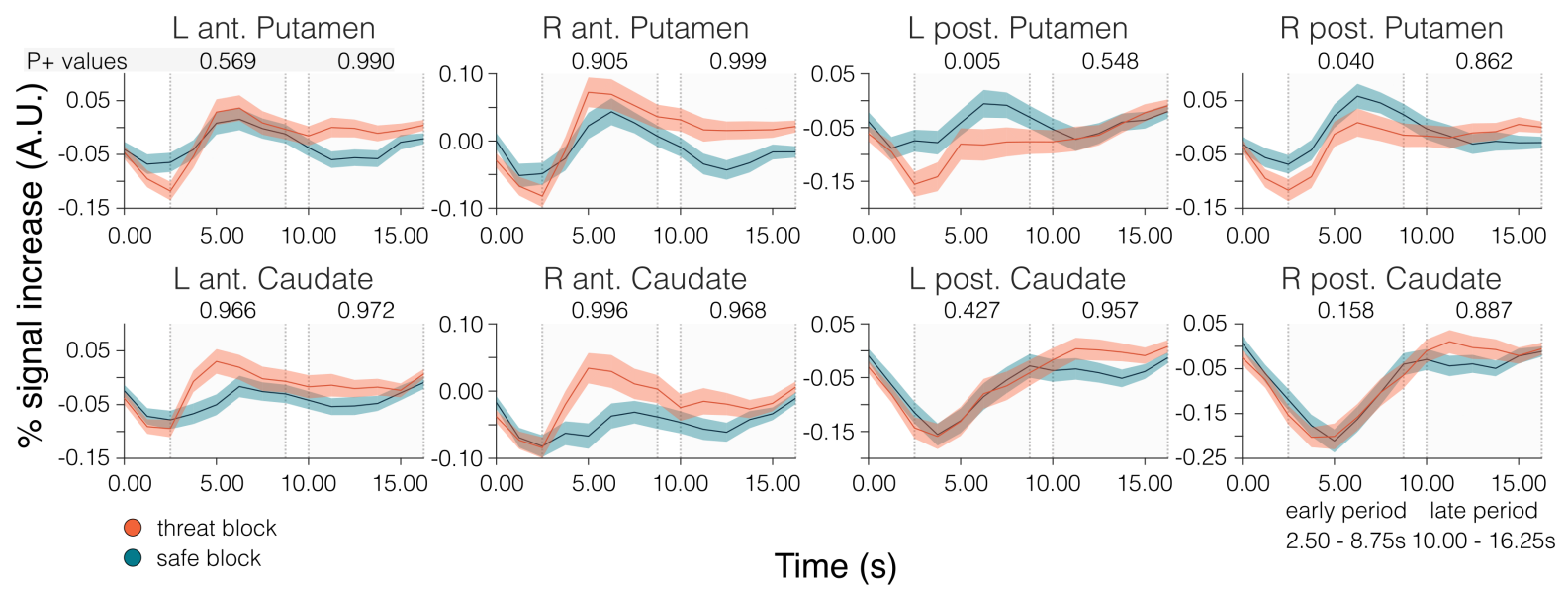

\section{Discussion}

Sustained anticipation of unpredictable aversive events generates anticipatory processing that is central to anxiety. In the present study, we examined how sustained threat was processed in the human brain. We used a relatively large sample $(N=109)$ and employed a Bayesian multilevel analysis approach to contrast threat and safe periods. Our analyses demonstrate that the effect of sustained threat is heterogeneous and distributed across the brain. Thus, the impact of threat is widespread, and not restricted to a small set of putatively emotion-related regions, such as the amygdala and the BST. Both transient and sustained as well as increased and decreased responses were observed. See Big Picture box.

Figure 13: Estimated responses for caudate and putamen. Error bands show $95 \%$ interval for standard error across participants to illustrate variability only. 
bioRxiv preprint doi: https://doi.org/10.1101/2021.07.11.451944; this version posted July 11, 2021. The copyright holder for this preprint (which was not certified by peer review) is the author/funder, who has granted bioRxiv a license to display the preprint in perpetuity. It is made available under aCC-BY-ND 4.0 International license.

$\mathrm{L}$ ant/sup ventral Thalamus $\mathrm{R}$ ant/sup ventral Thalamus
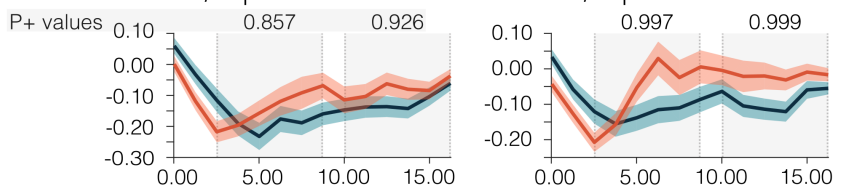

$\mathrm{L}$ ant/inf ventral Thalamus $\quad \mathrm{R}$ ant/inf ventral Thalamus
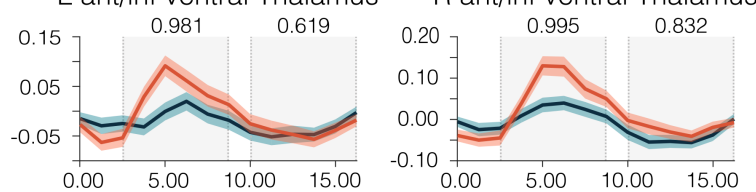

L lat/post ventral Thalamus R lat/post ventral Thalamus
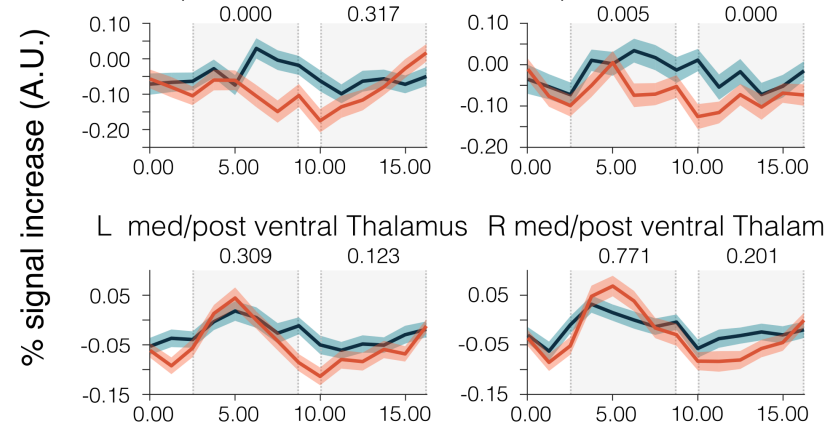

$\mathrm{L}$ ant/lat dorsal Thalamus
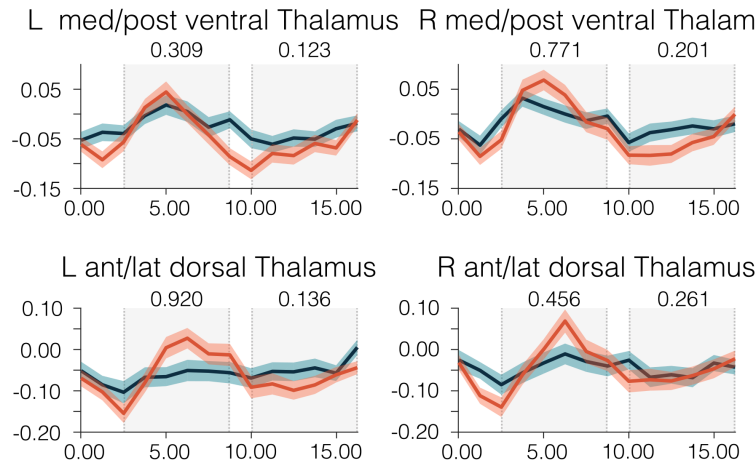

$\mathrm{R}$ ant/lat dorsal Thalamus

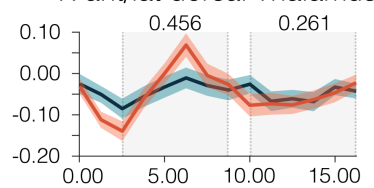

$\mathrm{L}$ ant/med dorsal Thalamus $\mathrm{R}$ ant/med dorsal Thalamus

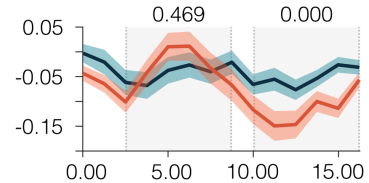

threat block

safe block

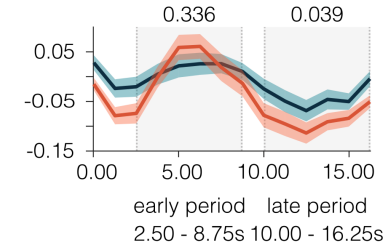

Time (s)
Figure 14: Estimated responses for thalamus. Error bands show $95 \%$ interval for standard error across participants to illustrate variability only. 
bioRxiv preprint doi: https://doi org/101101/2021 07.11.451944; this version posted July 11, 2021. The copyright holder for this preprin (which was not certified by peer review) is the author/funder, who has granted bioRxiv a license to display the preprint in perpetuity. It is made available under aCC-BY-ND 4.0 International license.

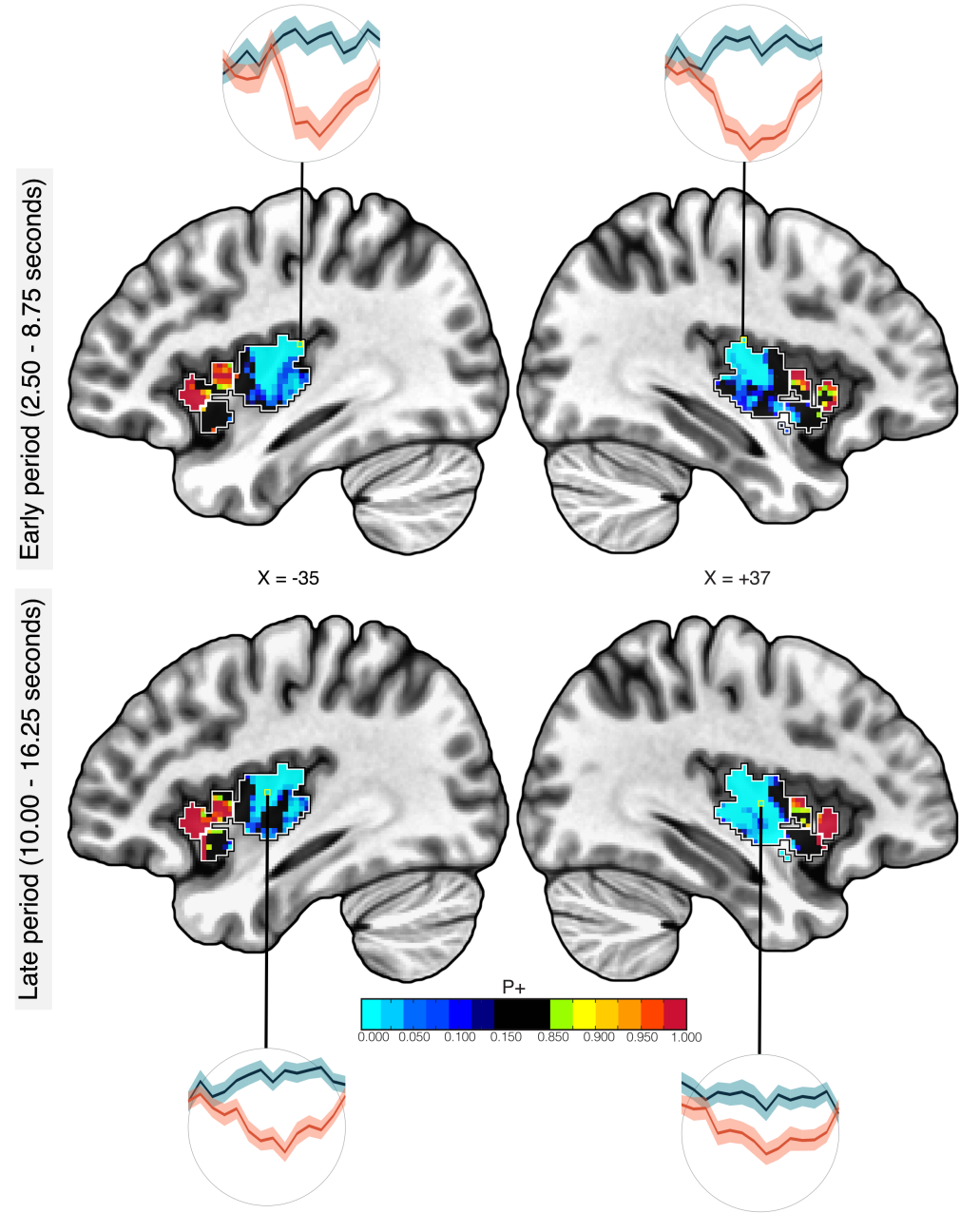

Early period (2.50 - 8.75 seconds)

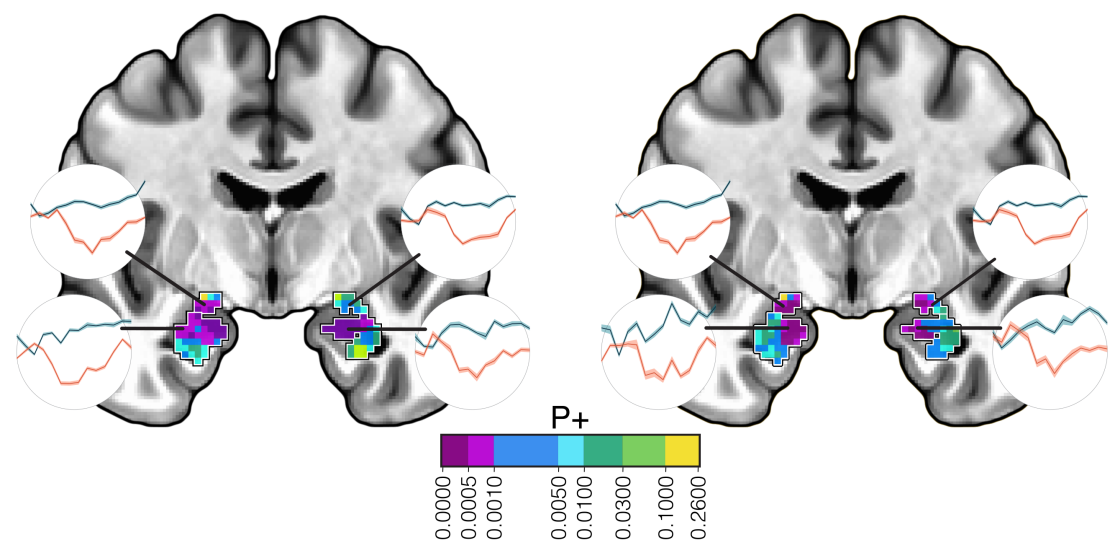

Figure 15: Voxelwise Bayesian multilevel model analysis: insula. Analyses were performed in the left and right insula, separately. White outlines indicate the regions employed in the ROI-level analysis. Sample voxel time series are shown.

Figure 16: Voxelwise Bayesian multilevel model analysis: amygdala. Analyses were performed in the left and right amygdala, jointly. White outlines indicate the regions employed in the ROIlevel analysis. Sample voxel time series are shown. 
bioRxiv preprint doi: https://doi.org/10.1101/2021.07.11.451944; this version posted July 11, 2021. The copyright holder for this preprint (which was not certified by peer review) is the author/funder, who has granted bioRxiv a license to display the preprint in perpetuity. It is made available under aCC-BY-ND 4.0 International license.

\section{Big Picture}

- Extended, uncertain threat engages the brain in a distributed fashion that prepares the organism to deal with the challenge. We believe that the focus on a few "typical" threat/aversive processing brain regions provides an impoverished and possibly misleading picture.

- Periods of anxious apprehension likely engage multiple mental processes, including those traditionally described as attentional, motivational, emotional, and action-related. Whereas there is value in attempting to isolate some of these processes (e.g., "purely" emotional), in more natural settings, they are jointly engaged and likely intertwined. We believe that always trying to disentangle them is counterproductive.

- Transitioning between threat and safe states, and vice versa, leads to a massive switch in brain responding likely involving most of the brain.

- Responses during threat and safe states are complex and multifaceted, involving both signal increase and decrease, as well as different patterns of transient and sustained signals.

\section{Key findings}

- Whereas some brain regions were engaged by threat, others were disengaged. Understanding both classes is necessary for a fuller appreciation of how the brain handles these states.

- Consistent with some, but not all, of the prior literature in humans, the amygdala was not engaged robustly during extended, uncertain threat.

- The bed nucleus of the stria terminalis was recruited transiently, not in a sustained fashion during threat.

- Regions that are part of the default network showed decreased responses during threat. It is possible that they disengage as the individual switches from self-related processing during safe conditions to preoccupation with the potential shock during threat.

- Some regions that showed decreased responses with threat may encode relative safety. Given evidence in rodents, this is possibly the case in the hippocampus.

- Responses often did not conform to canonical response shapes. Instead they showed nuanced/complex response profiles.

\section{Caveats}

- Because participants did not perform a task during threat/safe blocks, interpretation of the underlying processes is challenging.

- For example, interpretation of the responses in the posterior insula in terms of safety is speculative, despite related findings in rodents.

- For example, interpretation of the responses in the cerebellum in terms of timing mechanisms is speculative, but provide new avenues that can be investigated with experimental designs targeting this possibility.

\section{Threat-related increased responses}

During threat blocks, increased responses were observed in multiple brain regions. Evidence of transient responses was very strong in, among others, multiple sectors of the IFG, anterior MCC, pre-SMA, 
dorsolateral PFC, dorsal anterior insula, thalamus, and caudate. Evidence of sustained responses was strongest in different sectors of the IFG, dorsal anterior insula, posterior MCC, dorsolateral PFC, and putamen.

An extensive literature has described the engagement of the anterior MCC in aversive processing (for a review see, (Vogt, 2005)). ${ }^{2}$ Current evidence supports the idea that the anterior MCC is involved in emotion-, cognition-, and pain-related processing (Shackman et al., 2011); see also, (Misra and Coombes, 2015). In addition, meta-analyses suggest that the anterior MCC plays a central, integrative role in emotion regulation (Kohn et al., 2014), and is part of a core system for implementing self-control across emotion and action domains (Langner et al., 2018). The present study adds to this literature by showing that this region is transiently engaged when a threat context is initially experienced, and closely replicates a previous finding by our lab ((McMenamin et al., 2014); see also (Hasler et al., 2007; Schlund et al., 2013)). 3

The dorsal anterior insula, particularly on the right, exhibited sustained responses that were greater for threat, consistent with other empirical findings (Alvarez et al., 2011; Somerville et al., 2013). Indeed, several conceptual frameworks implicate the anterior insula in the processing of sustained threat, and have suggested that impaired processing of this area underlies anxiety disorders (Paulus and Stein, 2006; Picó-Pérez et al., 2017). Notably, we observed enhanced responses during threat only in the dorsal, not ventral anterior insula. These results are in contrast with proposals that suggest that the ventral anterior insula is more tuned to emotion-related processing whereas the dorsal sector is more tuned to cognitive-related processing (Kurth et al., 2010; Uddin et al., 2017).

In the present study, the dorsolateral PFC showed sustained activation during threat. Although this brain sector is often associated with cognitive functions, it is also involved during affective processing. Consistent with our results, studies have reported sustained signals lasting up to 30 seconds in the dorsolateral PFC (Hur et al., 2020; Andreatta et al., 2015; Wood et al., 2015; Qin et al., 2009). 4

Surprisingly, responses in the BST were relatively transient, whereas we had expected them to exhibit sustained responses during the block period given evidence of more sustained responses in this region (Alvarez et al., 2011; Somerville et al., 2013; McMenamin et al., 2014; Hur et al., 2020). Other regions exhibited sustained responses, including the right dorsolateral PFC, the right anterior putamen, among others. 5

Although threat-related research tends to focus on a few select structures (e.g., amygdala and medial PFC), there are increasing efforts to understand how distributed/large-scale circuits are involved. For example, in a review of fear and anxiety, Lüthi and colleagues (Tovote et al., 2015) described the participation of the amygdala, hippocampus, hypothalamus, PAG, thalamus, BST, medial PFC, and ventral striatum (including subregions of these structures), among others.
${ }^{2}$ In sharp contrast with the notion that the rostral ACC and the anterior MCC (also called dorsal ACC in some studies) are specialized in terms of emotional and cognitive processes, respectively (Bush et al., 2000).

${ }^{3}$ But see (Alvarez et al., 2011) and (Hur et al., 2020) for evidence of a more sustained response profile.

${ }^{5}$ Note that the skin conductance level was not sustained throughout the block duration either (see Figure 6). However, transient skin conductance responses were not due to uneven distribution of shocks, as these events were equally distributed throughout the block, including

towards the end of the block.

${ }^{4}$ In our experiment, the argument could be made that the involvement of the dorsolateral PFC is more related to "sustained attention" than threat-related proPicture for further discussion.
Picsentid 
Furthermore, it has been proposed that circuits involving multiple amygdala nuclei, PAG, medial PFC, and ventral striatum/nucleus accumbens participate in resolving between escape and freezing behavioral alternatives (LeDoux et al., 2017; Moscarello and LeDoux, 2013; Moscarello and Hartley, 2017); see also (llango et al., 2014).

In this context, it is noteworthy that we observed robust responses to threat in the striatum, in both the anterior caudate and the anterior putamen. The involvement of the anterior putamen was sustained, and to a some extent that of the anterior caudate, too. Note that because the block period did not require any response, and because both conditions required the same final type of motor response, it is unlikely that the differential response was substantially driven by motor-related processing. In this regard, the distinct response pattern in the posterior caudate is relevant, as it exhibits a tendency to be stronger for threat only during the late period.

Our results revealed a diverse set of response patterns across nuclei of the thalamus. Both anterior nuclei (superior and inferior) of the ventral thalamus exhibited stronger responses for threat, which were particularly robust and sustained in the right hemisphere. This pattern contrasted to that of the medial and lateral nuclei of the ventral thalamus.

\section{Threat-related decreased responses}

Multiple brain regions respond vigorously when threats are encountered or experienced. But it is also noteworthy that multiple brain regions respond less strongly during threat relative to safe, as observed here and in other studies (Limbachia et al., 2021; Mobbs et al., 2010). In our study, because no task was required during blocks, it is possible that decreased responses were related to routine processing in default network regions. The idea is that a region (say, PCC) is engaged during periods without an overt task, such as during safe blocks. However, during a threat block, these regions are not recruited as much, as the individual is now preoccupied with the potential shock.

It is noteworthy that some of the regions exhibiting decreased signals did not overlap with the default network. ${ }^{6}$ For example, our medial OFC ROI was entirely more ventral relative to parts of the medial OFC that are observed in the default network. The ROI that we called IFG2 (see Figure 2) had very minimal overlap (2-3 voxels) with the default network. In addition, the posterior insula showed marked decreases. Among subcortical regions, decreased responses were observed in the ventral thalamus, posterior caudate, and parts of the cerebellum (see below) not typically linked to the default network. Combined, these results indicate that several brain regions are less engaged during threat relative to safe not because they are part of the default network but due to other aspects potentially linked to safety-related processing (see below for further discussion of the posterior insula).

\footnotetext{
${ }^{6}$ To probe this issue for cortical regions, we investigated potential overlap by comparing our ROIs to the masks available in the so-called Schaefer parcellation (Schaefer et al., 2018).
} 
bioRxiv preprint doi: https://doi.org/10.1101/2021.07.11.451944; this version posted July 11, 2021. The copyright holder for this preprint (which was not certified by peer review) is the author/funder, who has granted bioRxiv a license to display the preprint in perpetuity. It is made available under aCC-BY-ND 4.0 International license.

The status of amygdala responses to sustained threat in humans is unclear. Whereas some investigators have reported increased responses (Schlund et al., 2013), several others have actually observed decreases (Choi et al., 2012; McMenamin et al., 2014; Pruessner et al., 2008; Wager et al., 2009). Here, we observed weaker responses for threat in all amygdala ROIs. Furthermore, the response evolution indicated that signals during threat decreased relative to safe during the early period, and remained lower during the late period. The voxelwise analysis confirmed these results, demonstrating that they did not result from the ROI-averaging process. At the same time, the analysis showed that the most robust differences were observed in relatively dorsal parts. Thus, in line with several other imaging studies, under the conditions of extended, uncertain threat of our experiment, the amygdala did not exhibit increased responses (but see Hur et al. 2020); instead the central/medial amygdala and basal amygdala exhibited a slowly evolving decreasing response. In passing, we not that while the amygdala is routinely associated with threat and fear-related processing, studies have observed safety-related signals in the basal amygdala using classical conditioning paradigms in both rats (Sangha et al., 2013) and non-human primates (Genud-Gabai et al., 2013).

In a previous study of threat controllability in humans, we observed responses in the posterior insula that were stronger during controllable relative to uncontrollable shocks (Limbachia et al., 2021). These findings were notable because in a threat controllability study in rodents, the posterior insula was suggested to encode a safety signal (Christianson et al., 2011). In the present study, the voxelwise Bayesian analysis identified voxels in the posterior insula with responses greater for safe relative to threat (also seen in the ROI-based analysis). The temporal evolution of the responses was also quite noteworthy, as the responses increased early on for both threat and safe, rapidly decreased for threat but stayed elevated for safe until the end of the block (the same pattern was observed in the ROI-based analysis). Combined, these results are consistent with the notion that the posterior insula potentially signals a state of relative safety.

Research over the past few decades has revealed that the cerebellum contributes to an array of non-motor functions, even including $\overline{\text { fear }}$ conditioning (Fullana et al., 2018). Lobule VI ROIs showed transient responses during threat blocks with rather modest increases relative to safe blocks (Figure 17; see also (Hur et al., 2020)). A qualitatively different pattern of results was observed in the Crus I ROIs, where responses were weaker for threat during the early period. Intriguingly, the responses appear to evolve with a somewhat ramping activity. It is noteworthy that a similar area of the cerebellum was reported to be involved in time perception and anticipation of future events (Apaydın et al., 2018). More broadly, the cerebellum is implicated in motor timing and planning (see Tanaka et al. 2020 for review). We speculate that the responses could be related to the anticipation of the anxiety rating following the block. Finally,

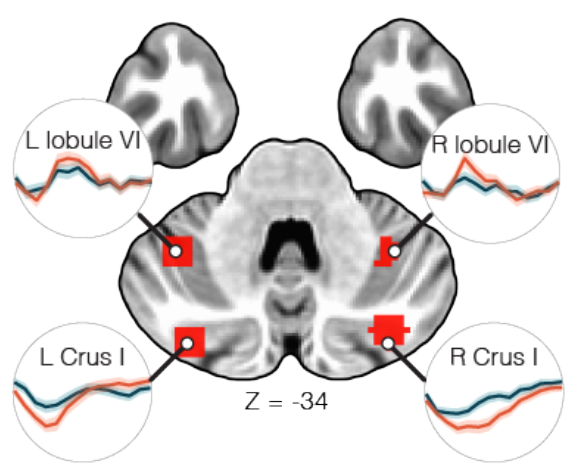

Figure 17: Cerebellum responses. Horizontal slice through the base of the brain showing the location of cerebellar ROIs, and the estimated ROI responses averaged across voxels during threat (red) and safe (blue). Error bands show $95 \%$ interval for standard error across participants to illustrate variability only. 
we note that the Crus I ROIs overlaps with sites that are correlated with the executive network during task-free conditions (Habas et al., 2009), highlighting the importance of further investigating cerebellar contributions to diverse mental processes.

\section{Conclusions}

The present study investigated sustained threat-related processing across brain regions previously discussed in the threat-related literature. We employed Bayesian multilevel modeling to estimate effect strength when comparing threat versus safe periods. Our study showed that periods of uncertain threat engage a broad, distributed set of brain regions, which displayed a diverse set of response profiles, including transient and sustained, increased or decreased responses. Periods of anxious apprehension are likely to engage a number of mental processes, including those traditionally described as attentional, motivational, emotional, and action-related, among others (but see (Cisek, 2019; Pessoa et al., 2021). Whereas there is value in attempting to isolate some of these processes (say, the more "purely" emotional), in more natural settings, they are jointly present and likely intertwined. In this context, our experiment uncovered a rich repertoire of response patterns during both threat and safe states, showing the multifaceted ways in which the brain is engaged during these two states.

Acknowledgements. We acknowledge Chirag Limbachia for work on data analysis during early stages of this project, and thank Gang Chen for discussions concerning statistical analysis. Research was supported by the National Institute of Mental Health (Ro1 MHo71589). 
bioRxiv preprint doi: https://doi.org/10.1101/2021.07.11.451944; this version posted July 11, 2021. The copyright holder for this preprint (which was not certified by peer review) is the author/funder, who has granted bioRxiv a license to display the preprint in perpetuity. It is made available under aCC-BY-ND 4.0 International license. 


\section{References}

Ruben P Alvarez, Gang Chen, Jerzy Bodurka, Raphael Kaplan, and Christian Grillon. Phasic and sustained fear in humans elicits distinct patterns of brain activity. Neuroimage, 55(1):389-400, 2011. DOI: 10.1016/j.neuroimage.2010.11.057.

Marta Andreatta, Evelyn Glotzbach-Schoon, Andreas Mühlberger, Stefan M Schulz, Julian Wiemer, and Paul Pauli. Initial and sustained brain responses to contextual conditioned anxiety in humans. Cortex, 63:352-363, 2015. DOI: 10.1016/j.cortex.2014.09.014.

Nihal Apaydın, Sertaç Üstün, Emre H. Kale, İpek Çelikağ, Halise D. Özgüven, Bora Baskak, and Metehan Çiçek. Neural Mechanisms Underlying Time Perception and Reward Anticipation. 12:115, 2018. ISSN 1662-5161. DOI: 10.3389/fnhum.2018.00115.

B Avants, N Tustison, and Song G. Advanced normalization tools: V1.o. The Insight Journal, 618, 2009.

Emily A Boeke, Justin M Moscarello, Joseph E LeDoux, Elizabeth A Phelps, and Catherine A Hartley. Active avoidance: neural mechanisms and attenuation of pavlovian conditioned responding. Journal of Neuroscience, 37(18):4808-4818, 2017. DOI: 10.1523/jneurosci.326116.2017 .

George Bush, Phan Luu, and Michael I Posner. Cognitive and emotional influences in anterior cingulate cortex. Trends in cognitive sciences, 4(6):215-222, 2000. DOI: 10.1016/s1364-6613(0o)01483-2.

Katherine S Button, John PA Ioannidis, Claire Mokrysz, Brian A Nosek, Jonathan Flint, Emma SJ Robinson, and Marcus R Munafò. Power failure: why small sample size undermines the reliability of neuroscience. Nature reviews neuroscience, 14(5):365-376, 2013. DOI: $10.1038 /$ nrn3475.

Paul-Christian Bürkner. brms: An R Package for Bayesian Multilevel Models Using Stan. Journal of Statistical Software, 8o(1), 2017. ISSN 1548-7660. DOI: 10.18637/jss.vo8o.io1.

Newton Sabino Canteras, Leonardo Barbosa Resstel, Leandro José Bertoglio, Antonio de Pádua Carobrez, and Francisco Silveira Guimaraes. Neuroanatomy of anxiety. Behavioral Neurobiology of Anxiety and Its Treatment, pages 77-96, 2009. Dor: $10.1007 / 785420097$. 
bioRxiv preprint doi: https://doi org/10.1101/2021.07.11.451944; this version posted July 11, 2021. The copyright holder for this preprint (which was not certified by peer review) is the author/funder, who has granted bioRxiv a license to display the preprint in perpetuity. It is made available under aCC-BY-ND 4.0 International license.

26

Gang Chen, Ziad S Saad, Nancy E Adleman, Ellen Leibenluft, and Robert W Cox. Detecting the subtle shape differences in hemodynamic responses at the group level. Frontiers in Neuroscience, 9:375, 2015. DOI: 10.3389 /fnins.2015.00375.

Gang Chen, Yaqiong Xiao, Paul A Taylor, Justin K Rajendra, Tracy Riggins, Fengji Geng, Elizabeth Redcay, and Robert W Cox. Handling multiplicity in neuroimaging through bayesian lenses with multilevel modeling. Neuroinformatics, 17(4):515-545, 2019. DOI: $10.1101 / 238998$.

Gang Chen, Paul A Taylor, Robert W Cox, and Luiz Pessoa. Fighting or embracing multiplicity in neuroimaging? neighborhood leverage versus global calibration. NeuroImage, 206:116320, 2020. DOI: $10.1101 / 706747$.

Gang Chen, Paul A Taylor, Joel Stoddard, Robert W Cox, Peter A Bandettini, and Luiz Pessoa. Dichotomous thinking and informational waste in neuroimaging. bioRxiv, 2021. DOI: 10.1101/2021.05.09.443246.

Jong Moon Choi, Srikanth Padmala, and Luiz Pessoa. Impact of state anxiety on the interaction between threat monitoring and cognition. Neuroimage, 59(2):1912-1923, 2012. DOI: 10.1016/j.neuroimage.2011.08.102.

John P Christianson, Joshua H Jennings, Thomas Ragole, Johana GN Flyer, Alexander M Benison, Daniel S Barth, Linda R Watkins, and Steven F Maier. Safety signals mitigate the consequences of uncontrollable stress via a circuit involving the sensory insular cortex and bed nucleus of the stria terminalis. Biological psychiatry, $70(5): 458-464$, 2011. DOI: 10.1016/j.biopsych.2011.04.004.

Paul Cisek. Resynthesizing behavior through phylogenetic refinement. Attention, Perception, \& Psychophysics, 81(7):2265-2287, 2019. DOI: 0.3758/s13414-019-01760-1.

Robert W. Cox. AFNI: Software for Analysis and Visualization of Functional Magnetic Resonance Neuroimages. Computers and Biomedical Research, 29(3):162-173, 1996. ISSN 00104809. DOI: 10.1006/cbmr.1996.0014.

Henk R Cremers, Tor D Wager, and Tal Yarkoni. The relation between statistical power and inference in fmri. PloS one, 12(11):e0184923, 2017. DOI: 10.1371/journal.pone.0184923.

Michael Davis and Changjun Shi. The extended amygdala: are the central nucleus of the amygdala and the bed nucleus of the stria terminalis differentially involved in fear versus anxiety? Annals of the New York Academy of Sciences, 877(1):281-291, 1999. DoI: 10.1111/j.17496632.1999.tbog273.x.

K.J. Friston, J. Ashburner, S.J. Kiebel, T.E. Nichols, and W.D. Penny, editors. Statistical Parametric Mapping: The Analysis of Functional Brain Images. Academic Press, 2007. 
Miquel A. Fullana, Anton Albajes-Eizagirre, Carles Soriano-Mas, Bram Vervliet, Narcís Cardoner, Olívia Benet, Joaquim Radua, and Ben J. Harrison. Fear extinction in the human brain: A metaanalysis of fMRI studies in healthy participants. Neuroscience $\mathcal{E}$ Biobehavioral Reviews, 88:16-25, 2018. ISSN 01497634. DOI: 10.1016/j.neubiorev.2018.03.002.

Andrew Gelman and Jennifer Hill. Data analysis using regression and multilevel/hierarchical models. Cambridge university press, 2006. DOI: 10.1017/cbo9780511790942.

Andrew Gelman, Jennifer Hill, and Masanao Yajima. Why we (usually) don't have to worry about multiple comparisons. Journal of Research on Educational Effectiveness, 5(2):189-211, 2012. DOI: 10.1080/19345747.2011.618213.

R. Genud-Gabai, O. Klavir, and R. Paz. Safety Signals in the Primate Amygdala. Journal of Neuroscience, 33(46):17986-17994, 2013. ISSN 0270-6474, 1529-2401. DOI: 10.1523/JNEUROSCI.1539-13.2013.

C Habas, N Kamdar, D Nguyen, K Prater, C F Beckmann, V Menon, and M D Greicius. Distinct Cerebellar Contributions to Intrinsic Connectivity Networks. Journal of Neuroscience, 29(26):8586-8594, 2009. ISSN 0270-6474. DOI: 10.1523/jneurosci.1868-09.2009.

Gregor Hasler, Stephen Fromm, Ruben P Alvarez, David A Luckenbaugh, Wayne C Drevets, and Christian Grillon. Cerebral blood flow in immediate and sustained anxiety. Journal of Neuroscience, (23): 6313-6319, 2007. DOI: 10.1523/jneurosci.5369-06.2007.

Erno J Hermans, Hein JF Van Marle, Lindsey Ossewaarde, Marloes JAG Henckens, Shaozheng Qin, Marlieke TR Van Kesteren, Vincent C Schoots, Helena Cousijn, Mark Rijpkema, Robert Oostenveld, et al. Stress-related noradrenergic activity prompts large-scale neural network reconfiguration. Science, 334(6059):1151-1153, 2011. DOI: 10.3410/f.13484057.793460464.

Erno J Hermans, Marloes JAG Henckens, Marian Joëls, and Guillén Fernández. Dynamic adaptation of large-scale brain networks in response to acute stressors. Trends in neurosciences, 37(6):304-314, 2014. DOI: $10.1016 /$ j.tins.2014.03.006.

Juyoen Hur, Jason F. Smith, Kathryn A. DeYoung, Allegra S. Anderson, Jinyi Kuang, Hyung Cho Kim, Rachael M. Tillman, Manuel Kuhn, Andrew S. Fox, and Alexander J. Shackman. Anxiety and the neurobiology of temporally uncertain threat anticipation. The Journal of Neuroscience, 40(41):7949-7964, 2020. ISSN 0270-6474, 1529-2401. DOI: 10.1523/JNEUROSCI.0704-20.2020.

Juan Eugenio Iglesias, Cheng-Yi Liu, Paul M Thompson, and Zhuowen $\mathrm{Tu}$. Robust brain extraction across datasets and comparison with publicly available methods. IEEE Transactions on Medical Imaging, 30:1617-1634, 2011. DOI: 10.1109/TMI.2011.2138152. 
bioRxiv preprint doi: https://doi.org/10.1101/2021.07.11.451944; this version posted July 11, 2021. The copyright holder for this preprint (which was not certified by peer review) is the author/funder, who has granted bioRxiv a license to display the preprint in perpetuity. It is made available under aCC-BY-ND 4.0 International license.

Anton Ilango, Jason Shumake, Wolfram Wetzel, and Frank W Ohl. Contribution of emotional and motivational neurocircuitry to cuesignaled active avoidance learning. Frontiers in behavioral neuroscience, 8:372, 2014. DOI: 10.3389/fnbeh.2014.00372.

Thorsten Kienast, Ahmad R Hariri, Florian Schlagenhauf, Jana Wrase, Philipp Sterzer, Hans Georg Buchholz, Michael N Smolka, Gerhard Gründer, Paul Cumming, Yoshitaka Kumakura, et al. Dopamine in amygdala gates limbic processing of aversive stimuli in humans. Nature neuroscience, 11(12):1381-1382, 2008. DOI: 10.1038/nn.2222.

Floris Klumpers, Marijn CW Kroes, Johanna MP Baas, and Guillén Fernández. How human amygdala and bed nucleus of the stria terminalis may drive distinct defensive responses. Journal of neuroscience, 37(40):9645-9656, 2017. DoI: 10.1523/jneurosci.3830-16.2017.

Nils Kohn, Simon B Eickhoff, Maryse Scheller, Angela R Laird, Peter T Fox, and Ute Habel. Neural network of cognitive emotion regulation - an ale meta-analysis and macm analysis. Neuroimage, 87: 345-355, 2014. DoI: 10.1016/j.neuroimage.2013.11.001.

Florian Kurth, Karl Zilles, Peter T Fox, Angela R Laird, and Simon B Eickhoff. A link between the systems: functional differentiation and integration within the human insula revealed by meta-analysis. Brain Structure and Function, 214(5-6):519-534, 2010. DOI: 10.1007/so0429010-0255-Z.

Iris Lange, Zuzana Kasanova, Liesbet Goossens, Nicole Leibold, Chris I. De Zeeuw, Therese van Amelsvoort, and Koen Schruers. The anatomy of fear learning in the cerebellum: A systematic metaanalysis. Neuroscience \& Biobehavioral Reviews, 59:83-91, 2015. ISSN 0149-7634. DOI: 10.1016/j.neubiorev.2015.09.019.

Robert Langner, Susanne Leiberg, Felix Hoffstaedter, and Simon B Eickhoff. Towards a human self-regulation system: common and distinct neural signatures of emotional and behavioural control. Neuroscience \& Biobehavioral Reviews, 90:400-410, 2018. DOI: 10.1016/j.neubiorev.2018.04.022.

Joseph E LeDoux, Justin Moscarello, Robert Sears, and Vincent Campese. The birth, death and resurrection of avoidance: a reconceptualization of a troubled paradigm. Molecular psychiatry, 22(1):24-36, 2017. DOI: $10.1038 / \mathrm{mp} .2016 .166$.

Chirag Limbachia, Kelly Morrow, Anastasiia Khibovska, Christian Meyer, Srikanth Padmala, and Luiz Pessoa. Controllability over stressor decreases responses in key threat-related brain areas. Communications biology, 4(1):1-11, 2021. DOI: 10.1101/2020.07.11.198762.

Richard McElreath. Statistical rethinking: A Bayesian course with examples in $R$ and Stan. Chapman and Hall/CRC, 2018. Dor: $10.1201 / 9781315372495$. 
Brenton W McMenamin, Sandra JE Langeslag, Mihai Sirbu, Srikanth Padmala, and Luiz Pessoa. Network organization unfolds over time during periods of anxious anticipation. Journal of Neuroscience, 34(34): 11261-11273, 2014. DOI: 10.1523/jneurosci.1579-14.2014.

Christian Meyer, Srikanth Padmala, and Luiz Pessoa. Dynamic threat processing. Journal of cognitive neuroscience, 31(4):522-542, 2019. DOI: $10.1101 / 183798$.

Gaurav Misra and Stephen A Coombes. Neuroimaging evidence of motor control and pain processing in the human midcingulate cortex. Cerebral cortex, 25(7):1906-1919, 2015. DoI: 10.1093/cercor/bhuoo1.

Dean Mobbs, Rongjun Yu, James B Rowe, Hannah Eich, Oriel FeldmanHall, and Tim Dalgleish. Neural activity associated with monitoring the oscillating threat value of a tarantula. Proceedings of the National Academy of Sciences, 107(47):20582-20586, 2010. DOI: 10.1073/pnas.1009076107.

Josep Moreno-Rius. The cerebellum in fear and anxiety-related disorders. Progress in Neuro-Psychopharmacology and Biological Psychiatry, 85: 23-32, 2018. ISSN 0278-5846. DOI: 10.1016/j.pnpbp.2018.04.002.

Justin M Moscarello and Catherine A Hartley. Agency and the calibration of motivated behavior. Trends in cognitive sciences, 21(10):725-735, 2017. DOI: 10.1016/j.tics.2017.06.008.

Justin M Moscarello and Joseph E LeDoux. Active avoidance learning requires prefrontal suppression of amygdala-mediated defensive reactions. Journal of Neuroscience, 33(9):3815-3823, 2013. DOI: 10.1523/jneurosci.2596-12.2013.

Denis Paré and Gregory J Quirk. When scientific paradigms lead to tunnel vision: lessons from the study of fear. npj Science of Learning, 2 (1):1-8, 2017. DOI: 10.1038/s41539-017-0007-4.

Martin P Paulus and Murray B Stein. An insular view of anxiety. Biological psychiatry, 6o(4):383-387, 2006. DOI: 10.3171/2009.6.FOCUSogio2.

Luiz Pessoa, Loreta Medina, and Ester Desfilis. Mental categories and the vertebrate brain: the neural basis of behavior. 2021. DOI: 10.31219/osf.io/8cmhg.

Maria Picó-Pérez, Joaquim Radua, Trevor Steward, José M Menchón, and Carles Soriano-Mas. Emotion regulation in mood and anxiety disorders: a meta-analysis of fmri cognitive reappraisal studies. Progress in Neuro-Psychopharmacology and Biological Psychiatry, 79:96-104, 2017. DOI: 10.26226/morressier.5971be81d462b8o29ob52c31.

Jens C Pruessner, Katarina Dedovic, Najmeh Khalili-Mahani, Veronika Engert, Marita Pruessner, Claudia Buss, Robert Renwick, Alain Dagher, Michael J Meaney, and Sonia Lupien. Deactivation of the limbic system during acute psychosocial stress: evidence from 
bioRxiv preprint doi: https://doi org/10.1101/2021.07.11.451944; this version posted July 11, 2021. The copyright holder for this preprint (which was not certified by peer review) is the author/funder, who has granted bioRxiv a license to display the preprint in perpetuity. It is made available under aCC-BY-ND 4.0 International license.

positron emission tomography and functional magnetic resonance imaging studies. Biological psychiatry, 63(2):234-240, 2008. DOI: 10.1016/j.biopsych.2007.04.041.

Raimon H.R. Pruim, Maarten Mennes, Jan K. Buitelaar, and Christian F. Beckmann. Evaluation of ICA-AROMA and alternative strategies for motion artifact removal in resting state fMRI. NeuroImage, 112: 278-287, 2015. ISSN 10538119. DOI: 10.1016/j.neuroimage.2015.02.063.

Shaozheng Qin, Erno J Hermans, Hein JF van Marle, Jing Luo, and Guillén Fernández. Acute psychological stress reduces working memory-related activity in the dorsolateral prefrontal cortex. Biological psychiatry, 66(1):25-32, 2009. DOI: 10.1016/j.biopsych.2009.03.006.

S. Sangha, J. Z. Chadick, and P. H. Janak. Safety Encoding in the Basal Amygdala. Journal of Neuroscience, 33(9):3744-3751, 2013. ISSN 0270-6474, 1529-2401. DOI: 10.1523/JNEUROSCI.3302-12.2013.

Alexander Schaefer, Ru Kong, Evan M Gordon, Timothy O Laumann, Xi-Nian Zuo, Avram J Holmes, Simon B Eickhoff, and BT Thomas Yeo. Local-global parcellation of the human cerebral cortex from intrinsic functional connectivity mri. Cerebral cortex, 28(9):3095-3114, 2018. DOI: 10.1093/cercor/bhxi79.

Michael W Schlund, Caleb D Hudgins, Sandy Magee, and Simon Dymond. Neuroimaging the temporal dynamics of human avoidance to sustained threat. Behavioural brain research, 257:148-155, 2013. DOI: 10.1016/j.bbr.2013.09.042.

David J Scott, Mary M Heitzeg, Robert A Koeppe, Christian S Stohler, and Jon-Kar Zubieta. Variations in the human pain stress experience mediated by ventral and dorsal basal ganglia dopamine activity. Journal of Neuroscience, 26(42):10789-10795, 2006. DOI: 10.1523/jneurosci.2577-06.2006.

Alexander J Shackman and Andrew S Fox. Contributions of the central extended amygdala to fear and anxietycontributions of the central extended amygdala to fear and anxiety. Journal of Neuroscience, 36(31):8050-8063, 2016. DOI: 10.1523/jneurosci.o982-16.2016.

Alexander J Shackman, Tim V Salomons, Heleen A Slagter, Andrew S Fox, Jameel J Winter, and Richard J Davidson. The integration of negative affect, pain and cognitive control in the cingulate cortex. Nature Reviews Neuroscience, 12(3):154-167, 2011. DOI: 10.1038/nrn2994.

David W Shattuck and Richard M Leahy. BrainSuite: An automated cortical surface identification tool. Medical Image Analysis, page 14, 2002.

Stephen M. Smith, Mark Jenkinson, Mark W. Woolrich, Christian F. Beckmann, Timothy E.J. Behrens, Heidi Johansen-Berg, Peter R. Bannister, Marilena De Luca, Ivana Drobnjak, David E. Flitney, Rami K. Niazy, James Saunders, John Vickers, Yongyue Zhang, 
Nicola De Stefano, J. Michael Brady, and Paul M. Matthews. Advances in functional and structural MR image analysis and implementation as FSL. NeuroImage, 23:S208-S219, 2004. ISSN 10538119. DOI: 10.1016/j.neuroimage.2004.07.051. URL https://linkinghub. elsevier.com/retrieve/pii/S1053811904003933.

Leah H Somerville, Dylan D Wagner, Gagan S Wig, Joseph M Moran, Paul J Whalen, and William M Kelley. Interactions between transient and sustained neural signals support the generation and regulation of anxious emotion. Cerebral cortex, 23(1):49-60, 2013. DoI: 10.1093/cercor/bhr373.

CD Spielberger, RL Gorsuch, and RE Lushene. Stai manual. palo alto, ca: Consulting psychologists press, 1970 .

Kartik K Sreenivasan and Mark D'Esposito. The what, where and how of delay activity. Nature Reviews Neuroscience, 20(8):466-481, 2019. DOI: 10.1038/s41583-019-0176-7.

Masaki Tanaka, Jun Kunimatsu, Tomoki W. Suzuki, Masashi Kameda, Shogo Ohmae, Akiko Uematsu, and Ryuji Takeya. Roles of the Cerebellum in Motor Preparation and Prediction of Timing. Neuroscience, page So306452220302724, 2020. DOI: 10.1016/j.neuroscience.2020.04.039.

Moriah E Thomason, J Paul Hamilton, and Ian H Gotlib. Stressinduced activation of the hpa axis predicts connectivity between subgenual cingulate and salience network during rest in adolescents. Journal of Child Psychology and Psychiatry, 52(10):1026-1034, 2011. DOI: 10.1111/j.1469-7610.2011.02422.x.

Philip Tovote, Jonathan Paul Fadok, and Andreas Lüthi. Neuronal circuits for fear and anxiety. Nature Reviews Neuroscience, 16(6):317-331, 2015. DOI: $10.1038 / \mathrm{nrn} 3945$.

Benjamin O Turner, Erick J Paul, Michael B Miller, and Aron K Barbey. Small sample sizes reduce the replicability of task-based fmri studies. Communications Biology, 1(1):1-10, 2018. DOI: 10.1038/s42003-018oo73-z.

Lucina Q Uddin, Jason S Nomi, Benjamin Hébert-Seropian, Jimmy Ghaziri, and Olivier Boucher. Structure and function of the human insula. Journal of clinical neurophysiology: official publication of the American Electroencephalographic Society, 34(4):300, 2017. DOI: 10.1097/wnp.000000000000377.

Brent A Vogt. Pain and emotion interactions in subregions of the cingulate gyrus. Nature Reviews Neuroscience, 6(7):533-544, 2005. Dor: 10.1038/nrn1704.

Tor D Wager, Vanessa A van Ast, Brent L Hughes, Matthew L Davidson, Martin A Lindquist, and Kevin N Ochsner. Brain mediators of cardiovascular responses to social threat, part ii: Prefrontal-subcortical 
pathways and relationship with anxiety. Neuroimage, 47(3):836-851, 2009. DOI: 10.1016/j.neuroimage.2009.05.044.

David L Walker, Donna J Toufexis, and Michael Davis. Role of the bed nucleus of the stria terminalis versus the amygdala in fear, stress, and anxiety. European journal of pharmacology, 463(1-3):199-216, 2003. DOI: 10.1016/s0014-2999(03)01282-2.

Kimberly H Wood, Muriah D Wheelock, Joshua R Shumen, Kenton H Bowen, Lawrence W Ver Hoef, and David C Knight. Controllability modulates the neural response to predictable but not unpredictable threat in humans. NeuroImage, 119:371-381, 2015. DoI: 10.1016/j.neuroimage.2015.06.086.

Shuxia Yao, Song Qi, Keith M Kendrick, and Dean Mobbs. Attentional set to safety recruits the ventral medial prefrontal cortex. Scientific reports, 8(1):1-9, 2018. DOI: $10.1101 / 249326$. 